\title{
CARACTERIZAÇÕES SOCIOECONÔMICA E ESPACIAL DO TRABALHO INFANTIL NAS REGIÕES RURAIS E URBANAS DO ESTADO DE MINAS GERAIS ${ }^{1}$
}

\author{
SOCIOECONOMIC AND SPACE CHARACTERIZATIONS OF \\ CHILD LABOR IN THE RURAL AND URBAN REGIONS OF THE \\ STATE OF MINAS GERAIS
}

\author{
Luiz Eduardo Vasconcelos Rocha \\ Doutor em Economia Rural, Professor Titular da Universidade Federal de São João Del Rei (UFSJ) \\ levrocha@ufsj.edu.br
}

\section{Resumo}

Há um consenso na literatura que o trabalho infantil é um fenômeno complexo e de difícil interpretação devido aos seus múltiplos fatores determinantes. Apesar do decréscimo do trabalho infantil nas últimas décadas, em 2010, segundo dados do Censo demográfico, $12,8 \%$ da população, entre 10 e 17 anos, estavam inseridos no mercado de trabalho no estado de Minas Gerais, representando o total de 345 mil crianças e adolescentes. Para analisar as características socioeconômicas do trabalho infantil utilizou-se a classificação sociológica, tendo em vista que ela vai além dos fatores puramente econômicos, incorporando questões culturais e sociais. Para obtermos uma divisão do território mais próxima da realidade, diferente da delimitação oficial, utilizou-se três critérios combinados para a definição dos espaços rural e urbano: delimitação administrativa, contingente populacional e densidade demográfica. Tendo em vista a dimensão territorial e a heterogeneidade social e cultural do estado, utilizou-se o método da Análise Exploratória de Dados Espaciais (AEDE), por meio da estatística I de Moran e da análise de identificação de clusters, para identificar o relacionamento e a distribuição do trabalho infantil entre os municípios do estado.

Palavras-chave: Trabalho infantil, Territórios rurais e urbanos, Estado de Minas Gerais, Classificação sociológica, Análise Exploratória de Dados Espaciais.

\begin{abstract}
There is a consensus that child labor it is a complex phenomenon and difficult to interpret because of its multiple determinants. Despite the decrease in child labor in recent decades, in 2010, according to the population census, $12.8 \%$ of the population between 10 and 17 , were inserted in the labor market in the state of Minas Gerais, which is the total of 345,000 children and adolescents. To analyze the socioeconomic characteristics of child labor sociological classification will be used, given that it goes beyond the purely economic factors, incorporating cultural and social issues. To obtain a division of the nearest territory of reality, different from the official definition, we used three criteria combined for the definition of rural and urban areas: administrative boundaries, population and demographic density. Given the territorial dimension and the social and cultural heterogeneity of the state, we used the method of Exploratory Spatial Data Analysis (ESDA), by Moran's I statistic and cluster identification analysis to identify the relationship and the distribution of child labor among the municipalities in the state.
\end{abstract}


Keywords: Child labor, Rural and urban territories, Minas Gerais state, Sociological classification, Exploratory Spatial Data Analysis.

\section{Introdução}

O trabalho exercido por crianças e adolescentes acompanha a evolução histórica da sociedade, incorporando características e significados éticos e morais segundo os períodos do desenvolvimento das relações produtivas na economia. A exploração da mão de obra infantil esteve presente desde a sociedade feudal, passando pela revolução industrial, e apesar da percepção atual que se trata de uma violação dos direitos humanos, em 2006, segundo dados da Organização Internacional do Trabalho (OIT, 2016), na economia mundial mais de 200 milhões de crianças, entre 5 e 17 anos, exerciam alguma atividade laboral. Atualmente, na sociedade globalizada, onde os acessos à informação e ao conhecimento, que determinam as possibilidades futuras das crianças adquirirem capital humano e social, o trabalho precoce, em certas circunstâncias, além de privá-las de usufruir da infância, limitam as possibilidades de obterem no futuro empregos de qualidade e boa remuneração.

No Brasil, o trabalho infantil esteve presente em todos os períodos do seu desenvolvimento, iniciando na colonização, onde as crianças foram submetidas a diversos tipos de ocupações, ligadas, em sua maioria, ao sustento das famílias. Posteriormente, no período da escravidão, entre os séculos XVIII e XIX, a exploração do trabalho infantil esteve voltada para as atividades domésticas e agrícolas. A partir da industrialização do país, na primeira metade do século XX, o problema se agravou, na medida em que os empresários, em busca de mão de obra barata, incorporaram grande parcela das crianças nas atividades industriais. Recentemente, segundo estimativas elaboradas a partir dos últimos censos demográficos (IBGE, 2004 e 2012), o trabalho infantil vem decrescendo em todas as regiões do país. Entre vários fatores que explicam essa queda, destacam-se a legislação que proíbe o trabalho infantil ${ }^{2}$, dependendo da fiscalização para o seu efetivo cumprimento, a adoção de programas sociais de transferência de renda com condicionalidades, entre elas a exigência da frequência das crianças na escola e, também, a queda recente da pobreza e da desigualdade da renda per capita domiciliar no país.

Entretanto, apesar do decréscimo do trabalho infantil nas últimas décadas, o Brasil apresenta ainda, segundo os dados do censo demográfico de 2010 (IBGE, 2012), cerca de 3,4 milhões de crianças e adolescentes, entre 10 e 17 anos, inseridos no mercado de 
trabalho, representando $12,4 \%$ da população total nesta faixa etária. O estado de Minas Gerais tem uma situação semelhante à do país, apresentando $12,8 \%$ da população, nesta mesma faixa etária, inserida no mercado de trabalho, o que representa o total de 345 mil crianças e adolescentes. No entanto, devido à heterogeneidade das condições socioeconômicas no estado, regiões como o Noroeste de Minas e Jequitinhonha chegam a ter, respectivamente, $17,1 \%$ e $16,7 \%$ de suas crianças no mercado de trabalho, apresentando números mais desfavoráveis do que a média do estado. Esses números demonstram que, apesar do decréscimo, o trabalho infantil ainda está longe de ser resolvido e diante dos graves danos ao futuro dessas crianças e da justiça social, tais como a privação do acesso à educação e a obtenção no futuro de empregos com maiores remunerações, perpetuando a situação de pobreza para gerações seguintes, torna-se de fundamental importância entender esse fenômeno, assumindo as suas características gerais e, mais importante, regionais, para que se possam propor medidas eficientes para a sua erradicação.

A pesquisa, ao propor, primeiramente, caracterizar as condições socioeconômicas do trabalho infantil no estado de Minas Gerais, utiliza a classificação sociológica, tendo em vista que ela vai além dos fatores puramente econômicos, incorporando questões culturais e sociais. O estado de Minas apresenta grande diversidade econômica, social e cultural, onde, por hipótese, assumimos que os fatores tanto de origem interna quanto externa, distintos entre as regiões do estado, podem influenciar de forma diversa o comportamento do trabalho infantil.

O trabalho infantil, como podemos observar, trata-se de um problema complexo na medida em que é influenciado por grande número de fatores que o condicionam, relacionados tanto às características interna da família quanto às condições externas. Todos esses fatores são analisados para as mesorregiões do estado de Minas Gerais. Essa análise se justifica, na medida em que, apesar da literatura do tema identificar a influência desses fatores sobre o trabalho infantil em diversas regiões e países, tanto desenvolvidos quanto em desenvolvimento, a forma e a intensidade de como eles agem podem diferir entre regiões ${ }^{3}$. Na presente pesquisa, optou-se por uma metodologia alternativa à oficial para identificar a localização dos domicílios nos territórios rurais e urbanos. No Brasil, diferente de outros países, a demarcação oficial utiliza o critério da delimitação administrativa, que classifica como urbana todas as sedes dos municípios e distritos, independente das características socioeconômicas e do seu tamanho (VEIGA, 2003). Essa 
demarcação superestima a população urbana, na medida em que, a cada Censo demográfico, observa-se o aumento da delimitação administrativa das áreas urbanas, estimulada, em parte, em função dos tributos destas áreas serem municipais enquanto no rural são de competência da união ${ }^{4}$. Para obtermos uma divisão do território mais abrangente, diferente da delimitação oficial, utilizamos três critérios combinados para a definição do espaço rural-urbano: delimitação administrativa, contingente populacional e densidade demográfica ${ }^{5}$.

A utilização de uma delimitação do rural e do urbano mais próxima da realidade é uma importante contribuição para o estudo do tema, tendo em vista, que os trabalhos realizados até então, segundo revisão bibliográfica, utilizam a delimitação oficial, disponibilizada para a realidade brasileira na Pnad e no Censo e, também, pela delimitação espacial ser um fator de grande influência no trabalho infantil. Segundo Muniz (2012), os domicílios localizados nas regiões rurais tendem a apresentar maior nível de trabalho infantil, tendo em vista que as famílias apresentam maior dificuldade de obterem trabalho de melhor qualidade, utilizando a mão de obra das crianças para complementar a renda e garantir a sobrevivência da família.

Em princípio, o arcabouço teórico da pesquisa parte do princípio que a inserção das crianças e dos adolescentes no mercado de trabalho é uma decisão da família que tem como fundamentação a maximização dos seus benefícios em um contexto intertemporal. Essa decisão ocorre simultaneamente na distribuição da alocação do tempo das crianças ao estudo. Neste sentido são observadas a seguintes possibilidades para a alocação do tempo das crianças, divididas em quatro classificações: crianças que não estudam e não trabalham (NENT), que estudam e não trabalham (ENT), não estudam e trabalham (NET) e, finalmente, estudam e trabalham (ET).

Em síntese, a partir da constatação que o combate ao trabalho infantil vai além da complementação da renda familiar, sendo importante a adoção de estratégias que levem em conta os seus mecanismos complementares, determinados por amplo conjunto de fatores condicionados por seu contexto regional. A pesquisa, assumindo essa pressuposição e levando em consideração o grande número de crianças inseridas no mercado de trabalho do estado, tem como proposta entender os determinantes do trabalho infantil em Minas Gerais em uma perspectiva espacial, identificando, através da Análise Exploratória de Dados Espaciais, o padrão de relacionamento e agrupamento do trabalho infantil entre os municípios do estado. 
Além das considerações introdutórias, o trabalho é constituído por mais quatro seções. A próxima seção descreve os procedimentos metodológicos. A terceira seção apresenta a caracterização socioeconômica do trabalho infantil e dos seus fatores determinantes, levando em consideração as mesorregiões, os territórios rural e urbano e as características das atividades econômicas dos domicílios. A quarta seção apresenta a análise espacial do trabalho infantil para os municípios do estado. E, finalmente, a quinta seção traz os comentários finais.

\section{Metodologia}

Nesta seção, serão descritos, primeiramente, o modelo neoclássico unitário da oferta de trabalho, que assume que a família toma uma decisão conjunta sobre a alocação dos recursos intrafamiliar; posteriormente, são descritas a fonte e as características dos dados secundários da pesquisa e a delimitação das variáveis regionais, quais sejam, os espaços rurais e urbanos; e, finalmente, um breve comentário metodológico sobre a análise espacial.

\section{Modelo unitário - a abordagem tradicional}

O tema que trata das decisões intrafamiliares na alocação do tempo das crianças e adolescentes entre trabalho e estudo tem demandado grande interesse da teoria econômica. Dois grupos de modelos foram desenvolvidos para representar a alocação intrafamiliar de recursos. O primeiro, denominado de modelo neoclássico unitário da oferta de trabalho, assume que a família toma uma decisão conjunta sobre a alocação dos recursos intrafamiliar. $\mathrm{O}$ segundo, denominado de modelo coletivo, assume a pressuposição que a alocação do tempo das famílias é resultado de um processo de barganha entre os seus membros. Essa seção descreve o modelo teórico neoclássico unitário, hipótese teórica da pesquisa.

O modelo unitário do comportamento familiar, na verdade, estende a teoria neoclássica do consumidor para o contexto familiar, demonstrando as escolhas de consumo e lazer sob a hipótese de maximização da utilidade. Essa abordagem assume que a família, apesar de ser constituída por diversos indivíduos, age como se fosse um único agente tomador de decisão capaz de maximizar uma única função de utilidade que capta as preferências de todos os membros da unidade familiar. Esse arcabouço teórico, 
assim como o problema do consumidor individual, quando aplicado para o caso das famílias resulta em uma função de demanda por bens e lazer conjunta para a família. Neste caso, assume-se implicitamente que a alocação de consumo e bem-estar no interior da família é irrelevante ou sistematicamente ótima, tornando-se importante apenas como a distribuição dos recursos ocorre entre as famílias (FERNANDES, 2008).

Essa forma de interpretar as decisões familiares apresenta a vantagem de se adequar perfeitamente ao tratamento microeconômico neoclássico da escolha do consumidor ${ }^{6}$. Sendo assim, deve-se ampliar para as escolhas das famílias, compreendida como unidade de análise, os teoremas de integralidade a partir da observação do seu comportamento e, ainda, satisfazer uma série de propriedades, tais como: aditividade, homogeneidade de grau zero e matriz de Slutsky simétrica e semi-definida negativa ${ }^{7}$. Ainda, segundo Vermeulen (2002), deve-se assumir a restrição denominada de Hipótese da renda conjunta que estabelece que a fonte de renda não laboral não tem nenhum papel no problema de alocação das famílias.

\section{Fontes dos dados, divisão territorial e caracterização das atividades econômicas dos domicílios}

A pesquisa utiliza como fonte os microdados da amostra do censo demográfico de 2010 (IBGE, 2012), que investiga detalhadamente as características de toda a população e dos domicílios do território nacional.

O Estado de Minas Gerais é constituído de 12 mesorregiões, 66 microrregiões e 853 municípios. A localização das mesorregiões está descrita na figura 1. Essa divisão territorial foi estabelecida pelo Instituto Brasileiro de Geografia e Estatística (IBGE), com a resolução PR-11, de $1^{\text {o }}$ de janeiro de 1990. As mesorregiões geográficas correspondem a áreas que apresentam formas de organização do espaço geográfico que lhes conferem identidade regional, a qual é determinada pelo processo social e pelas características naturais do espaço físico. As microrregiões são áreas territoriais menores que as mesorregiões e agrupam municípios com características físicas, sociais e econômicas de certa homogeneidade dentro de um mesmo estado (IBGE, 1998). 
Figura 1 - Mapa das mesorregiões do Estado de Minas Gerais

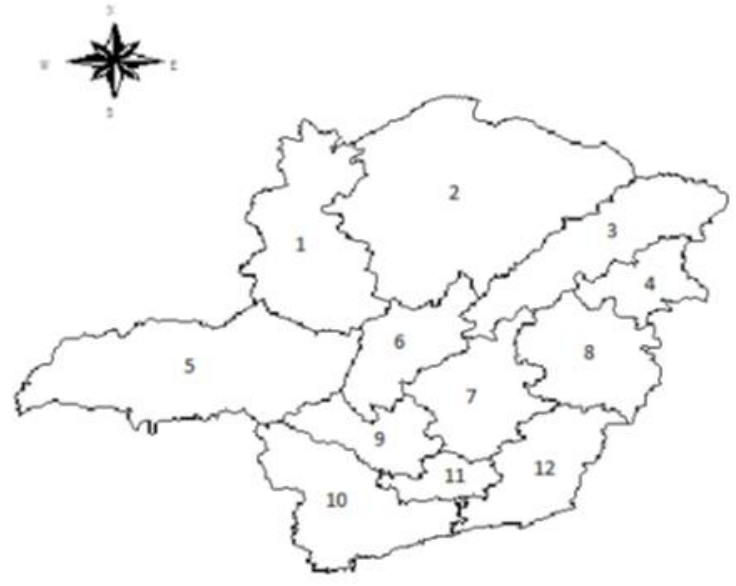

Fonte: Elaboração própria. Noroeste de Minas (1), Norte de Minas (2), Jequitinhonha (3), Vale do Mucuri (4), Triângulo Mineiro e Alto Paranaíba (5), Central Mineira (6), Metropolitana de Belo Horizonte (7), Vale do Rio Doce (8), Oeste de Minas (9), Sul e Sudoeste de Minas (10), Campos das Vertentes (11) e Zona da Mata (12).

Para a delimitação dos espaços urbano e rural, utiliza-se a metodologia proposta por Ney e Hoffmann (2009) que leva em consideração três critérios: i) delimitação administrativa, definição oficial apresentada nos Censos e Pnads, ii) contingência populacional e iii) densidade demográfica ${ }^{8}$. O território rural passa a ser constituído pelas áreas delimitadas pelas administrações oficialmente como rural, acrescida, ainda, pelas “cidades rurais" compostas pela população urbana das cidades com menos de 20 mil habitantes e com densidade demográfica menor que 60 habitantes por $\mathrm{Km}^{2}$. O território urbano se constitui dos espaços delimitados oficialmente como urbano, dividido em três categorias, quais sejam, “cidades pequenas", com população até 100 mil habitantes (as de menos de 20 mil habitantes deverá apresentar densidade demográfica superior a 60 habitantes por $\mathrm{Km}^{2}$ ), “cidades médias” com população entre 100 e 299 mil habitantes e as "cidades grandes", com população superior a 300 mil habitantes.

Na definição da variável ocupação domiciliar, considerou-se apenas os indivíduos adultos, acima de 18 anos de idade. O domicílio agrícola é aquele em que pelo menos um membro exerce atividade no setor agrícola e $67 \%$ ou mais da renda do trabalho advém de atividades agrícolas. Domicílios pluriativos são aqueles em que pelo menos um membro exerce atividade agrícola, mas menos de $67 \%$ da renda do trabalho vem de atividade agrícolas. Domicílios sem ocupação são aqueles em que não há membro que receba renda 
advinda do trabalho. E, finalmente, os domicílios não agrícolas são aqueles em que não há nenhum membro com atividade no setor agrícola9

\section{Análise exploratória de dados espaciais (AEDE)}

As AEDEs são úteis para estudar os diversos fenômenos entre regiões, dentre eles os socioeconômicos, levando-se em consideração o relacionamento e a distribuição dos dados no espaço. Essas análises, em geral, podem diagnosticar dois efeitos distintos: dependência e heterogeneidade espaciais. Para implementar a AEDE, utilizamos a Autocorrelação Global Univariada, por meio do I de Moran que identifica a autocorrelação entre a alocação do tempo das crianças e adolescentes entre estudo e trabalho nos municípios e também os LISA que buscam identificar agrupamentos espaciais significantes de valores similares em torno da observação nos municípios. Pelo amplo conhecimento na economia regional e pela limitação de espaço, essas metodologias não são apresentadas no trabalho. Esses métodos são descritos detalhadamente em Rocha e Fontes (2011).

\section{Análise empírica}

Nesta seção, primeiramente, é apresentada a divisão territorial do estado de Minas Gerais entre as áreas rural e urbana, utilizando para tanto a medida alternativa à metodologia oficial. A seguir, a partir dessa divisão territorial, são apresentadas as análises descritivas do trabalho infantil e dos seus fatores determinantes, relacionados tanto ao grupo de fatores de classificação interna e externa das famílias, levando em consideração as mesorregiões, os territórios rural e urbano que compõem o estado e as características econômicas dos domicílios. E, finalmente, é descrita a análise espacial das quatro classificações da alocação do tempo das crianças e adolescentes entre estudo e trabalho nos municípios do estado.

\section{População dos territórios rural e urbano do estado de Minas Gerais.}

A pesquisa, ao propor analisar os determinantes do trabalho infantil levando em consideração as especificidades dos territórios rural e urbano, inicialmente, depara-se com o desafio de definir esses espaços. Como ressaltado na indução, a medida oficial desses espaços territoriais no Brasil utiliza o critério da delimitação administrativa, que 
classifica como urbana todas as sedes dos municípios e distritos, independentemente de suas características socioeconômicas e do seu tamanho. E o mais grave é que esse critério, amplamente divulgado pelos levantamentos estatísticos do Instituto Brasileiro de Geografia e Estatística (IBGE), tais como a Pnad e o Censo Demográfico, é utilizado em várias pesquisar que subsidiam a elaboração de importantes políticas públicas no país.

Assumindo a inadequação dessa definição, utilizamos a metodologia de Ney e Hoffmann (2009), que propõe uma nova delimitação dos territórios rural e urbano para o estado de Minas Gerais. A tabela 1 apresenta o cálculo populacional para os territórios rural e urbano, utilizando, para tanto, a definição oficial e a alternativa, nos anos censitários de 1991, 2000 e 2010, permitindo verificar as significativas discrepâncias das medidas.

A partir da medida oficial, que assume a delimitação administrativa para os territórios, a população rural do estado decresceria, entre o período de 1991 a 2010, de 3,9 para 2,8 milhões de habitantes. Assumindo a medida alternativa, que incorpora à oficial as "cidades rurais", definidas como aquelas que apresentam população menor de 20 mil habitantes e densidade demográfica inferior a 60 habitantes por $\mathrm{Km}^{2}$, a população, no período, passaria de 6,3 para 5,9 milhões de habitantes. Ou seja, pela medida alternativa, o estado tem uma população rural bem maior e o seu decréscimo, no período, foi bem menor do que demonstram as estatísticas oficiais. A população urbana total, definida como a soma das populações urbanas das cidades pequenas, médias e grandes, cresceria, entre 1991 a 2010, de 9,4 para 13,6 milhões de habitantes.

Tabela 1 - População rural e urbana do estado de Minas Gerais, segundo as medidas oficial e alternativa para os anos de 1991, 2000 e 2010

\begin{tabular}{|c|c|c|c|c|c|c|c|}
\hline \multirow[t]{2}{*}{ Ano } & \multicolumn{3}{|c|}{ Rural } & \multicolumn{3}{|c|}{ Urbana } & \multirow[b]{2}{*}{ Total } \\
\hline & Oficial & Cidades & Total & Pequenas & Médias & Grandes & \\
\hline 1991 & 3.956.278 & $\begin{array}{c}2.362 .164 \\
(660)\end{array}$ & 6.318 .442 & $\begin{array}{c}4.439 .520 \\
(177)\end{array}$ & $\begin{array}{c}1.813 .523 \\
(12)\end{array}$ & $\begin{array}{c}3.171 .687 \\
\text { (4) }\end{array}$ & 9.424 .730 \\
\hline 2000 & 3.219 .670 & $\begin{array}{c}2.708 .512 \\
(641)\end{array}$ & 5.928 .182 & $\begin{array}{c}5.095 .134 \\
(189)\end{array}$ & $\begin{array}{c}2.571 .459 \\
(17)\end{array}$ & $\begin{array}{c}4.296 .724 \\
\text { (6) }\end{array}$ & 11.963.317 \\
\hline 2010 & 2.882.114 & $\begin{array}{c}3.027 .307 \\
(637)\end{array}$ & 5.909 .421 & $\begin{array}{c}5.364 .104 \\
(187)\end{array}$ & $\begin{array}{c}18 \\
(23)\end{array}$ & $\begin{array}{c}4.793 .953 \\
(6)\end{array}$ & 13.687.909 \\
\hline
\end{tabular}

Fonte: elaboração própria a partir dos microdados dos Censos Demográficos de 1991, 2000 e 2010. O valor entre parênteses representa o número de municípios segundo a tipologia das cidades.

Analisando ainda os dados da Tabela 1, é interessante observar que, em 1991, dos 853 municípios do estado, 660 eram considerados “cidades rurais”. Em 2010, eram 637, 
demonstrando que, no período, não houve alteração significativa nas tipologias dos municípios. Para as cidades urbanas, destacam-se as médias que, no período, passaram de 12 para 23 municípios. As pequenas cresceram de 177 para 187 e as grandes de 4 para 6. A População urbana desses municípios é de 4,7 milhões de cidadãos, representado $24,5 \%$ da população total do estado.

As cidades médias, com população entre 100 e 299 mil habitantes, foram as que mais cresceram tanto em número de municípios quanto em população, entre os anos de 1991 e 2010. Neste período, o número de municípios passou de 12 para 23 e a população urbana de 1,8 para 3,5 milhões de habitantes, chegando em 2010 a representar $18 \%$ da população total. As cidades pequenas, com população menor de 100 mil habitantes e densidade demográfico superior a $60 \mathrm{Km}^{2}$ para aquelas com menos de 20 mil habitantes, passou no período de 177 para 187 municípios e a população urbana aumentou de 4,4 para 5,3 milhões de cidadãos, representando $27 \%$ da população do estado. Em síntese, a medida oficial subestima o tamanho da população rural no estado e apresenta um quadro de sua dimensão territorial que não condiz com a realidade quando assumimos no seu conceito, além da dimensão administrativa, as características de densidade demográfica e contingência populacional.

A tabela 2 demonstra que, pela medida oficial, entre 1991 a 2010, a população rural passaria de $25,1 \%$ para $14 \%$ da população total do estado. Quando consideramos a medida alternativa, observa-se também decréscimo da população rural, mas as magnitudes alteram para queda de 40,1\% para 30,1\%. Outro fator a destacar é que essa queda ocorreu, principalmente, entre 2000 a 2010, em função do crescimento da população urbana, tendo em vista que a população rural, em termos absolutos, permaneceu praticamente constante em 5,9 milhões de habitantes.

Tabela 2 - Proporção das populações rural e urbana no estado de Minas Gerais, segundo as medidas oficial e alternativa para os anos de 1991, 2000 e 2010

\begin{tabular}{cccccc}
\hline Ano & Oficial & Alternativa & Total & \% Oficial & \% Alternativa \\
\hline 1991 & 3.956 .278 & 6.318 .442 & 15.743 .171 & 25.13 & 40.13 \\
2000 & 3.219 .670 & 5.928 .182 & 17.891 .499 & 17.99 & 33.13 \\
2010 & 2.882 .114 & 5.909 .421 & 19.597 .330 & 14.07 & 30.15 \\
\hline
\end{tabular}




\section{Condições de atividades das crianças e adolescentes}

A maioria dos trabalhos que abordam as atividades das crianças utiliza quatro categorias representativas que combinam a possibilidade da alocação do tempo das crianças entre a ociosidade, o estudo e o trabalho. Dentro dessa perspectiva, a Tabela 3 descreve, a partir da categorização proposta, as atividades das crianças mineiras, segundo as mesorregiões do estado, no ano de 2010. O estado, neste ano, tinha 2,7 milhões de crianças e adolescentes, entre 10 e 17 anos. Na condição de ociosidade, tendo em vista que as crianças não estudam nem trabalham, denominada de NENT, verificou-se 140 mil crianças, representando $5,1 \%$ da população nesta faixa etária no estado. Na condição de estudo e não trabalho, ENT, encontram-se $82,1 \%$ da população, com 2,2 milhões de crianças. Na condição de não estudo e trabalho, NET, encontram-se 3\%, com 80 mil crianças. E, finalmente, na condição de conciliar estudo e trabalho, ET, verificaram-se 269 mil crianças, representando $9,9 \%$ da população nesta faixa etária.

Tabela 3 - Percentual e total de crianças e adolescentes segundo as condições de atividades nas mesorregiões do estado de Minas Gerais no ano de 2010

\begin{tabular}{|c|c|c|c|c|c|}
\hline \multicolumn{6}{|l|}{ Mesorregiões } \\
\hline & NENT (\%) & ENT (\%) & NET $(\%)$ & ET $(\%)$ & Total \\
\hline Noroeste de Minas (1) & 4,9 & 78,0 & 3,1 & 14,0 & 57.410 \\
\hline Norte de Minas (2) & 5,8 & 80,1 & 3,0 & 11,1 & 267.448 \\
\hline Jequitinhonha (3) & 5,8 & 77,4 & 3,3 & 13,4 & 119.581 \\
\hline Vale do Mucuri (4) & 6,7 & 80,9 & 2,7 & 9,7 & 61.127 \\
\hline Triângulo Mineiro (5) & 5,2 & 80,3 & 3,0 & 11,5 & 274.877 \\
\hline Central Mineira (6) & 4,9 & 80,7 & 3,3 & 11,1 & 59.055 \\
\hline M. Belo horizonte (7) & 4,6 & 85,2 & 2,2 & 8,0 & 833.584 \\
\hline Vale do Rio Doce (8) & 6,3 & 81,8 & 3,1 & 8,8 & 241.040 \\
\hline Oeste de Minas (9) & 4,4 & 78,4 & 4,8 & 12,4 & 124.387 \\
\hline Sul de Minas (10) & 4,9 & 80,8 & 3,7 & 10,6 & 328.631 \\
\hline Campo Vertentes (11) & 3,7 & 86,8 & 2,2 & 7,3 & 73.672 \\
\hline Zona da Mata (12) & 5,4 & 81,8 & 3,3 & 9,6 & 290.711 \\
\hline Minas Gerais & 5,1 & 82,1 & 3,0 & 9,9 & 2.731.525 \\
\hline
\end{tabular}

Fonte: elaboração própria a partir dos microdados do Censo Demográficos de 2010 (IBGE, 2012).

Neste caso, somando-se as condições de atividade não estudo e trabalho, NET, e estudo e trabalho, ET, 12,9\% da população de crianças e adolescentes do estado, representando 349 mil indivíduos, exerciam alguma atividade laboral. Nas mesorregiões, essa participação altera em relação à situação verificada no estado. Nas regiões Noroeste 
de Minas (1), Jequitinhonha (3) e Oeste de Minas (9), observaram-se maior nível de trabalho infantil, com participação, respectivamente, de 17,1\%, 16,7\% e 17,3\% da população total de crianças e adolescentes. Por outro lado, as regiões de Belo Horizonte (7) e Campo das Vertentes (11) apresentaram menor nível de trabalho infantil, com participação, respectivamente, de $10,2 \%$ e $9,5 \%$.

Dentre as tipologias de atividades, vale destacar a situação das crianças e adolescentes que não estudam nem trabalham, NENT, representando, no estado, 5,1\% da população total. Apesar dessa baixa participação, em termos absolutos são 140 mil crianças em situação de vulnerabilidade, onde, em um período importante do processo de educação e formação, essas crianças estão ociosas e sem perspectivas. Essa situação é mais grave nas regiões do Vale Mucuri (4) e Vale do Rio Doce (8), com a participação de crianças nesta situação chegando a, respectivamente, 6,7\% e 6,3\%.

A tabelas 4 descreve, a partir da categorização proposta, as atividades das crianças mineiras, segundo as mesorregiões do estado, levando em consideração os territórios rural e urbano.

Tabela 4 - Proporção e total de crianças e adolescentes segundo as condições de atividades nos territórios rural $(\mathrm{R})$ e urbano (U) das mesorregiões do estado de Minas Gerais no ano de 2010

\begin{tabular}{|c|c|c|c|c|c|c|c|c|c|c|}
\hline \multicolumn{11}{|l|}{ Mesorregiões } \\
\hline & \multicolumn{2}{|c|}{ NENT (\%) } & \multicolumn{2}{|c|}{ ENT (\%) } & \multicolumn{2}{|c|}{ NET (\%) } & \multicolumn{2}{|c|}{ ET $(\%)$} & \multirow{2}{*}{$\begin{array}{l}\text { Total } \\
\text { R } \\
\end{array}$} & \multirow[b]{2}{*}{$\mathbf{U}$} \\
\hline & $\mathbf{R}$ & $\mathbf{U}$ & $\mathbf{R}$ & $\mathbf{U}$ & $\mathbf{R}$ & $\mathbf{U}$ & $\mathbf{R}$ & $\mathbf{U}$ & & \\
\hline Noroeste de Minas (1) & 4,8 & 5,0 & 76,9 & 79,1 & 3,1 & 3,1 & 15,3 & 12,8 & 27.697 & 29.713 \\
\hline Norte de Minas (2) & 6,5 & 5,0 & 76,1 & 84,4 & 3,4 & 2,6 & 14,0 & 8,0 & 139.777 & 127.670 \\
\hline Jequitinhonha (3) & 5,9 & 5,8 & 75,8 & 80,8 & 3,6 & 2,5 & 14,7 & 10,9 & 80.557 & 39.025 \\
\hline Vale do Mucuri (4) & 7,4 & 5,4 & 77,5 & 86,9 & 3,2 & 1,9 & 11,9 & 5,8 & 38.557 & 22.570 \\
\hline Triângulo Mineiro (5) & 6,4 & 4,8 & 75,4 & 81,8 & 3,8 & 2,8 & 14,4 & 10,6 & 64.037 & 210.841 \\
\hline Central Mineira (6) & 6,2 & 4,0 & 78,9 & 81,8 & 3,9 & 2,9 & 11,0 & 11,2 & 23.187 & 35.869 \\
\hline M. Belo horizonte (7) & 5,5 & 4,5 & 81,2 & 85,7 & 2,9 & 2,1 & 10,4 & 7,7 & 84.941 & 748.643 \\
\hline Vale do Rio Doce (8) & 6,8 & 5,6 & 78,1 & 85,0 & 3,8 & 2,6 & 11,3 & 6,9 & 106.613 & 133.932 \\
\hline Oeste de Minas (9) & 5,1 & 4,1 & 76,7 & 79,1 & 5,5 & 4,6 & 12,7 & 12,3 & 36.936 & 87.453 \\
\hline Sul de Minas (10) & 5,2 & 4,7 & 77,7 & 83,3 & 4,7 & 3,0 & 12,5 & 9,0 & 147.462 & 181.169 \\
\hline Campo Vertentes (11) & 4,3 & 3,3 & 82,6 & 89,2 & 3,4 & 1,5 & 9,7 & 6,0 & 26.585 & 47.087 \\
\hline Zona da Mata (12) & 6,0 & 4,9 & 76,9 & 85,5 & 4,5 & 2,3 & 12,6 & 7,2 & 125.470 & 165.241 \\
\hline Minas Gerais & 5,9 & 4,7 & 77,5 & 84,3 & 3,9 & 2,5 & 12,7 & 8,5 & 901.818 & 1.829.212 \\
\hline
\end{tabular}

Fonte: elaboração própria a partir dos microdados do Censo Demográfico de 2010.

Comparando os dados entre as regiões, observa-se que, com exceção para a tipologia estuda e não trabalha, ENT, nos territórios rurais a participação das crianças nas 
tipologias não estuda nem trabalha, NENT, não estuda e trabalha, NET, e, finalmente, estuda e trabalha, ET, supera a participação verificada nos territórios urbanos. Essa mesma relação se confirma quando analisamos as mesorregiões, ou seja, nas regiões urbanas o percentual de crianças apenas estudando supera ao verificado nas rurais, sendo que o percentual para as ociosas e as crianças que trabalham são inferiores. Isso demonstra que o território é um fator importante e que deve ser levado em conta na análise dos determinantes das escolhas das famílias na alocação do tempo das crianças entre a ociosidade, o estudo e o trabalho.

Para finalizar a presente seção, tornar-se importante relativizar a situação do trabalho infantil de Minas Gerais em relação aos demais estados brasileiros. Dos vinte e sete estados, Minas Gerais, ao apresentar 12,8\% da população de crianças e adolescentes trabalhando, torna-se o décimo quarto estado do país com maior incidência de trabalho infantil. Santa Catarina, estado localizado na região sul do país com altos índices de desenvolvimento, apresentou a maior incidência de trabalho infantil, 18,9\%, e o menor, Rio de Janeiro, apresentou 6,7\%.

Segundo Nascimento e Kassouf (2014), o Brasil, a partir da década de 1990, tem obtido importantes avanços no combate ao trabalho infantil. Utilizando a mesma tipologia de atividades do trabalho, os autores identificaram, entre 1992 a 2011, o aumento, para a faixa de crianças de 11 a 15 anos, da participação de 64,8\% para 89,4\% das crianças que apenas estudam e não trabalham, ENT. A participação das crianças que não estudam e nem trabalham, NENT, caiu de $8,7 \%$ para $2,5 \%$, das que conciliam os estudos com o trabalho, ET, passou de $16,4 \%$ para 7,4\% e, finalmente, aquelas que não estudam e apenas trabalham, NET, reduziu de $9,9 \%$ para apenas $0,6 \%$.

\section{Características socioeconômicas do trabalho infantil}

Nesta seção serão descritas algumas características socioeconômicas do trabalho infantil, cobrindo, portanto, as duas tipologias da alocação de tempo das crianças que incorporam a atividade laboral, quais sejam, a condição de conciliar os estudos com o trabalho, ET, com 269 mil crianças e adolescentes nesta categoria no estado, 9,8\% da população total, e a condição de apenas trabalhar, NET, com 80,7 mil crianças, representando $3 \%$ da população nesta faixa etária.

A tabela 5 descreve as características socioeconômicas das crianças e adolescentes que exercem alguma atividade laboral, levando em consideração as mesorregiões do 
estado de Minas Gerais. A primeira característica observada para o estado e as suas doze mesorregiões é que no caso em que as crianças e adolescentes apenas trabalham, (NET) verifica-se maior proporção de homens, sendo que na situação onde o trabalho é conciliado com o estudo, (ET), as proporções são bastante semelhantes entre os sexos.

Em certa medida, esses números explicam a maior frequência e o menor nível de abandono de crianças do sexo feminino do sistema de ensino. A segunda característica analisada refere-se à raça das crianças e adolescentes. No estado, a proporção de brancos para as situações de apenas trabalhar e conciliar o estudo com o trabalho é de $46 \%$, sendo que para as mesorregiões essas proporções são bastante distintas. No caso das regiões mais pobres do estado, tais como o Norte de Minas (2), Jequitinhonha (3) e Vale do Mucuri (4) a maioria das crianças em situação de trabalho é parda ou negra, sendo que as brancas representam por volta de $25 \%$ da população total. Por outro lado, nas regiões mais ricas como Oeste de Minas (9) e o Sul de Minas (10), a maioria das crianças em situação de trabalho é branca, com, respectivamente, 60 e $70 \%$ da população total.

Outro fator relevante na caracterização socioeconômica das crianças e adolescentes em situação de trabalho é a condição da renda domiciliar. Dentre as variáveis explicativas abordadas nos estudos do trabalho infantil, a renda é a que apresenta os resultados mais controversos. Vários estudos, entre eles Araujo (2010) e Kassouf (2002), mostram que a renda familiar reduz a probabilidade das crianças trabalharem e aumentam a probabilidade de apenas estudarem, outros, tais como Barros et al. (1994), não identificam relação significativa da renda com essas probabilidades e, finalmente, tem aqueles estudos, entre eles Bhalotra e Heady (2003), que identificam uma relação direta, ou seja quando a renda da família eleva-se aumenta-se também a probabilidade das crianças exercerem alguma atividade laboral. 
Caracterizações socioeconômica e espacial do trabalho

Luiz Eduardo Vasconcelos Rocha

infantil nas regiões rurais e urbanas do estado de Minas Gerais

Tabela 5 - Características socioeconômicas das crianças e adolescentes que apenas trabalham (NET) e que conciliam o estudo com

\begin{tabular}{|c|c|c|c|c|c|c|c|c|c|c|c|c|}
\hline \multicolumn{13}{|l|}{ Mesorregiões } \\
\hline & & $\operatorname{sexo}(M)^{1}$ & $\operatorname{Raça}(B)^{2}$ & Pobre $^{3}$ & C. Mulher ${ }^{4}$ & S. Rem. ${ }^{5}$ & Horas $^{6}$ & Renda $^{7}$ & \multicolumn{4}{|c|}{ Setor ocupação domiciliar ${ }^{8}$} \\
\hline & & $(\%)$ & $(\%)$ & $(\%)$ & $(\%)$ & $(\%)$ & & $(\mathbf{R} \$)$ & N.Agri. (\%) & Agri. (\%) & Plur (\%) & S. Ocu. $(\%)$ \\
\hline \multirow[t]{2}{*}{ Noroeste de Minas (1) } & NET & 63,1 & 33,8 & 7,3 & 28,9 & 7,6 & 40,3 & 3,31 & 53,80 & 30,50 & 5,90 & 9,90 \\
\hline & ET & 48,5 & 31,8 & 8,6 & 33,4 & 47,93 & 28,11 & 2,15 & 49,50 & 26,60 & 12,70 & 11,20 \\
\hline \multirow[t]{2}{*}{ Norte de Minas (2) } & NET & 61,3 & 25,5 & 17,2 & 28,2 & 27,2 & 37,0 & 2,61 & 35,20 & 31,60 & 10,20 & 23,00 \\
\hline & ET & 49,5 & 26,4 & 20,9 & 31,7 & 95,63 & 24,77 & 2,63 & 41,70 & 31,10 & 9,40 & 17,80 \\
\hline \multirow{2}{*}{ Jequitinhonha (3) } & NET & 61,5 & 24,2 & 20,6 & 32,8 & 28,4 & 36,8 & 2,47 & 28,50 & 35,30 & 13,50 & 22,60 \\
\hline & ET & 49,3 & 23,3 & 25,1 & 37,7 & 87,92 & 24,76 & 2,19 & 37,20 & 34,20 & 12,10 & 16,60 \\
\hline \multirow[t]{2}{*}{ Vale do Mucuri (4) } & NET & 61,6 & 24,4 & 16,6 & 30,5 & 23,9 & 35,8 & 2,84 & 34,70 & 31,00 & 8,10 & 26,20 \\
\hline & ET & 50,4 & 25,2 & 19,2 & 36,8 & 83,68 & 23,72 & 2,92 & 39,20 & 33,60 & 8,70 & 18,50 \\
\hline \multirow[t]{2}{*}{ Triângulo Mineiro (5) } & NET & 59,6 & 57,0 & 1,9 & 30,3 & 5,1 & 41,3 & 3,74 & 58,10 & 24,20 & 9,20 & 8,50 \\
\hline & ET & 52,6 & 58,9 & 1,4 & 34,8 & 19,24 & 29 & 4,21 & 64,10 & 18,60 & 12,60 & 4,70 \\
\hline \multirow[t]{2}{*}{ Central Mineira (6) } & NET & 60,7 & 42,4 & 4,1 & 31,0 & 4,2 & 41,4 & 3,64 & 59,20 & 17,60 & 11,00 & 12,30 \\
\hline & ET & 50,9 & 43,6 & 4,0 & 36,4 & 20,29 & 28,21 & 2,67 & 67,00 & 17,40 & 10,80 & 4,80 \\
\hline \multirow[t]{2}{*}{ M. Belo horizonte (7) } & NET & 56,2 & 39,0 & 2,7 & 35,6 & 4,9 & 38,4 & 4,93 & 71,30 & 9,30 & 8,90 & 10,50 \\
\hline & ET & 50,9 & 42,1 & 2,3 & 39,0 & 25,08 & 26,29 & 6,18 & 75,50 & 8,50 & 9,90 & 6,10 \\
\hline \multirow[t]{2}{*}{ Vale do Rio Doce (8) } & NET & 60,4 & 34,4 & 9,1 & 28,7 & 14,3 & 38,1 & 2,80 & 43,40 & 28,80 & 9,60 & 18,20 \\
\hline & ET & 50,9 & 36,0 & 9,6 & 32,6 & 52,62 & 25,22 & 2,20 & 52,20 & 25,40 & 10,40 & 12,00 \\
\hline \multirow[t]{2}{*}{ Oeste de Minas (9) } & NET & 59,2 & 58,9 & 2,2 & 28,0 & 3,2 & 41,2 & 3,60 & 65,80 & 15,30 & 10,80 & 8,10 \\
\hline & ET & 50,8 & 60,2 & 1,9 & 32,6 & 18,26 & 29,01 & 3,74 & 70,80 & 13,60 & 11,60 & 4,00 \\
\hline \multirow[t]{2}{*}{ Sul de Minas (10) } & NET & 60,2 & 69,2 & 3,6 & 26,8 & 5,7 & 41,2 & 3,46 & 38,80 & 39,90 & 12,80 & 8,50 \\
\hline & ET & 52,1 & 70,5 & 3,0 & 32,1 & 27,3 & 28,42 & 3,50 & 52,80 & 27,80 & 14,90 & 4,40 \\
\hline \multirow[t]{2}{*}{ Campo Vertentes (11) } & NET & 59,7 & 57,1 & 5,6 & 30,9 & 6,8 & 39,6 & 3,03 & 46,70 & 29,80 & 13,20 & 10,30 \\
\hline & ET & 53,2 & 59,5 & 5,0 & 35,2 & 41,46 & 24,83 & 3,64 & 63,20 & 18,30 & 10,00 & 8,60 \\
\hline \multirow[t]{2}{*}{ Zona da Mata (12) } & NET & 59,3 & 50,8 & 6,8 & 29,6 & 12,6 & 40,1 & 3,09 & 39,60 & 37,20 & 11,00 & 12,30 \\
\hline & ET & 50,9 & 52,4 & 6,5 & 34,0 & 43,18 & 27,84 & 3,92 & 49,80 & 31,20 & 11,10 & 7,90 \\
\hline \multirow[t]{2}{*}{ Minas Gerais } & NET & 58,9 & 46,2 & 5,6 & 31,2 & 10,00 & 39,37 & 3,61 & 50,6 & 26,1 & 10,4 & 12,9 \\
\hline & ET & 51,0 & 46,5 & 6,0 & 35,6 & 37,97 & 26,87 & 4,22 & 58,4 & 21,7 & 11,3 & 8,6 \\
\hline
\end{tabular}

trabalho (ET), nas mesorregiões do estado de Minas Gerais, 2010.

Fonte: elaboração própria a partir dos microdados do Censo Demográfico de 2010. (1) Proporção de crianças e adolescentes do sexo masculino; Proporção de raça branca; (3) Proporção de pobres, segundo linha monetária de pobreza de R \$ 140,00 para a renda per capita domiciliar líquida; (4) Proporção residentes em domicílios chefiados por mulheres; (5) Proporção sem remuneração monetária; (6) Horas médias de trabalho na semana; (7) Remuneração média por hora trabalhada e, finalmente, (8) Proporção residentes segundo os setores de ocupação domiciliar: domicílios não agrícolas, agrícolas, pluriativos e sem ocupação. 
No estado de Minas Gerais, segundo os dados da tabela 5, assumindo a linha monetária de pobreza de $\mathrm{R} \$ 140,00$, utilizada pelo Atlas do Desenvolvimento humano do Brasil (PNUD, IPEA; FJP; 2013), das crianças e adolescentes que apenas trabalham (NET) e conciliam o estudo com o trabalho (ET), apenas, respectivamente, 5,6\% e 6,0\% são consideradas pobres. Naturalmente, nas regiões menos desenvolvidas do estado, tais como o Norte de Minas (2), Jequitinhonha (3) e Vale do Mucuri (4), as proporções de pobres entre o grupo de crianças que apenas trabalham, (NET), elevam-se, respectivamente para $17,2 \%, 20,6 \%$ e $16,6 \%$; no caso das crianças e adolescentes que conciliam o estudo com o trabalho (ET), as proporções elevam-se, respectivamente, para $20,9 \%, 25,1 \%$ e 19,2\%. Por outro lado, nas regiões do estado mais populosas e desenvolvidas, tais como o Triangulo Mineiro (5) e Metropolitana de Belo Horizonte (7), do grupo de crianças que apenas trabalham, (NET), apenas, respectivamente, 1,9\% e 2,7\% do grupo de crianças que apenas trabalham, (NET), apenas, respectivamente, 1,9\% e 2,7\% são considerados pobres e no grupo que estuda e trabalha, (ET), 1,4\% e 2,3\%.

Esses dados demonstram a grande heterogeneidade regional da população de crianças e adolescentes pobres que exercem alguma atividade laboral no estado. Deve-se ressaltar que na maioria das suas doze mesorregiões, ao contrário do senso comum, a maior parte da população de crianças e adolescentes que trabalham, a partir da definição adotada através da linha monetária, não pode ser considerada pobre.

Os domicílios chefiados por mulheres são considerados um fator de vulnerabilidade, tendo em vista as discriminações de gênero que resultam, em geral, em serviços de baixa qualificação e como consequência em menores remunerações. No estado, 35,6\% das crianças e adolescentes que conciliavam o estudo com o trabalho, (ET), e 31,2\% que apenas trabalhavam, (NET), residiam em domicílios chefiados por mulheres. Em todas as mesorregiões observam-se proporções próximas às verificados no estado, sendo importante ressaltar que nos domicílios com crianças e adolescentes que conciliam o estudo com o trabalho a proporção de mulheres chefes sempre foi superior aos domicílios com crianças que apenas trabalham. Isso demonstra, de certa forma, a importância da influência das mulheres na decisão das crianças, apesar de trabalharem, continuarem a frequentar a escola.

A identificação da forma de remuneração do trabalho infantil é uma importante caracterização para compreender a inserção das crianças no mercado de trabalho. Essa remuneração pode se dar monetariamente ou através de produtos que podem ser 
comercializados ou utilizados no próprio consumo da família e, em alguns casos, onde observam-se a maior exploração e vulnerabilidade, as crianças podem não receber nenhuma remuneração. Os dados disponíveis no Censo Demográfico que permitem quantificar o nível da remuneração do trabalho infantil referem-se apenas ao retorno monetário. Neste sentido, torna-se inicialmente importante identificar as crianças que recebem alguma remuneração monetária das que recebem produtos ou nenhuma remuneração.

No estado, das crianças e adolescentes que conciliavam o estudo com o trabalho, (ET), 38\% não recebiam remuneração monetária, sendo que essa proporção varia consideravelmente entre as mesorregiões. Nas regiões menos desenvolvidas, Norte de Minas (2), Jequitinhonha (3) e Vale do Mucuri (4), respectivamente, 95,6\%, 87,9\% e $83,6 \%$ das crianças e adolescentes não recebiam remuneração monetária, enquanto nas regiões mais desenvolvidas, Metropolitana de Belo Horizonte (7) e Oeste de Minas (9), essa proporção reduz respectivamente, para $25,08 \%$ e $18,2 \%$. No caso das crianças que apenas trabalham, (NET), apesar das diferenças regionais, a proporção das que não recebem remuneração monetária reduz consideravelmente. Para o estado essa proporção foi de 10\%, para a mesorregião Jequitinhonha (3), com maior participação de sem remuneração, a proporção foi de 28,4\% e a menor, Oeste de Minas (9), com a penas 3,2\%.

Outra informação importante descrita na tabela 5 é a quantidade de horas semanais que as crianças e adolescentes trabalharam. No estado, as crianças que apenas trabalhavam, (NET), ficaram ocupadas, em média, 39,3 horas na semana, sendo que as que conciliavam o trabalho com o estudo, (ET), apresentaram menor tempo de ocupação, em média, 26,8 horas. Esse comportamento foi verificado também em todas as mesorregiões do estado, com as horas trabalhadas, para ambos os estratos de ocupação, bem próximas das verificadas no estado.

Para analisarmos o nível da remuneração monetária das crianças e adolescentes por unidade de hora trabalhada, torna-se necessário um termo de referência. No período de coleta das informações do Censo em agosto de 2010, o salário mínimo corrente era de $\mathrm{R} \$ 510,00$. Considerando quarenta horas trabalhadas na semana, o salário bruto por hora trabalhada seria de $\mathrm{R} \$ 3,10$. No estado, tanto a remuneração das crianças e adolescentes que apenas trabalhavam, (NET), quanto as que conciliavam o estudo com o trabalho, (ET), apresentaram remuneração média acima do salário mínimo, recebendo, respectivamente $R \$ 3,61$ e $R$ \$ 4,22. Nas mesorregiões, as remunerações apresentaram 
grande dispersão em relação à verificada no estado. Enquanto no Jequitinhonha (3) as remunerações (NET) e (ET) eram, respectivamente de $R$ \$ 2,47 e $R$ \$ 2,19, na região Metropolitana de Belo Horizonte (7) chegavam, respectivamente, a R \$ 4,96 e R\$ 6,18.

Dois pontos merecem destaque nesta análise. O primeiro é que em oito das doze mesorregiões do estado a remuneração média da hora trabalhada das crianças que conciliam o trabalho com o estudo superam a remuneração das que apenas trabalham, demonstrando que mesmo no trabalho infantil a educação pode representar maiores retornos de remuneração. E o segundo ponto, que deverá ser discutido mais à frente, ao analisarmos a renda média, devemos levar em conta o nível de dispersão dos rendimentos.

Ainda na tabela 5, são descritos os setores de ocupação dos domicílios das crianças e adolescentes. Como era de se esperar, dado o nível de desenvolvimento econômico, grande parte das crianças, no estado e na maioria das mesorregiões, tanto para o estrato (NET) quanto para o (ET), residem em domicílios não agrícola, acompanhados dos domicílios agrícolas e, finalmente, com participação menor, porém bem próximas, para os domicílios pluriativos e sem ocupação. Entretanto, essa distribuição se altera para os municípios menos desenvolvidos, que apresentam participação dos domicílios não agrícola e agrícola próxima dos 30\%, menor participação dos pluriativos e maior proporção de crianças residentes nos domicílios sem ocupação, em relação ao verificado no estado. Enquanto no estado $12,9 \%$ das crianças e adolescentes que apenas trabalhavam, (NET), residiam em domicílios caracterizados como sem ocupação, essa proporção nas mesorregiões Norte de Minas (2), Jequitinhonha (3) e Vale do Mucuri (4), eleva-se, respectivamente, para 23\%, 22,6\% e 26,2\%, demonstrando que as condições sociais destas regiões apresentam maior vulnerabilidade em relação às demais regiões do estado.

As tabelas 6 e 7 descrevem algumas características socioeconômicas das crianças e adolescentes que exerciam atividade laboral, considerando o setor de ocupação domiciliar e, respectivamente, as diferenças de sexo e raça.

Como era de se esperar a maior concentração de crianças residentes na área rural ocorre nos domicílios agrícolas e na área urbana, nos domicílios não agrícola. Em todos os setores de ocupação, tanto para as regiões rural e urbana, observam-se a predominância de crianças do sexo masculino. A proporção de crianças sem remuneração monetária na região rural, para todos os setores, é bem superior ao verificado nas áreas urbanas. As informações das horas semanais trabalhadas e da remuneração monetária, tabela 6, 
Caracterizações socioeconômica e espacial do trabalho infantil nas regiões rurais e urbanas do estado de Minas Gerais

permitem as seguintes conclusões sobre as diferenças de sexo. Primeiro, os homens, em todos os setores e regiões trabalham mais horas semanais que as mulheres e, segundo, levando em consideração os valores do primeiro quartis, $75 \%$ das crianças do sexo masculino trabalham mais que 20 horas semanais e do sexo feminino mais que 15 horas.

Tabela 6 - Características socioeconômicas das crianças e adolescentes que exercem alguma atividade laboral, considerando o sexo e o setor de ocupação domiciliar nas regiões rural e urbana do estado, 2010

Setor domic.

\begin{tabular}{|c|c|c|c|c|c|c|c|c|c|c|c|c|c|c|c|}
\hline & \multirow{3}{*}{$\begin{array}{r}\text { Prop. }^{1} \\
(\%)\end{array}$} & \multirow{3}{*}{$\begin{array}{l}\text { Sexo }^{2} \\
\text { M (\%) }\end{array}$} & \multirow{3}{*}{$\begin{array}{c}\text { S.Rem. } \\
(\%)\end{array}$} & \multicolumn{6}{|c|}{ Horas na semana } & \multicolumn{5}{|c|}{ Remuneração hora } & \multirow{2}{*}{$\begin{array}{l}(\mathbf{R} \$) \\
\text { Q. }\end{array}$} \\
\hline & & & & 10 & & & & 3 & & & Q. & 20 & 2. & & \\
\hline & & & & $\mathbf{M}$ & $\mathbf{F}$ & $\mathbf{M}$ & $\mathbf{F}$ & $\mathbf{M}$ & $\mathbf{F}$ & $\mathbf{M}$ & $\mathbf{F}$ & $\mathbf{M}$ & $\mathbf{F}$ & $\mathbf{M}$ & $\mathbf{F}$ \\
\hline \multicolumn{16}{|l|}{ Rural } \\
\hline Não agrícola & 32,3 & 58,3 & 24,1 & 20 & 15 & 35 & 25 & 44 & 40 & 1,39 & 1,00 & 2,50 & 1,70 & 3,18 & 2,89 \\
\hline Agrícola & 41,9 & 66,3 & 41,1 & 20 & 12 & 32 & 24 & 44 & 40 & 1,25 & 0,87 & 2,42 & 1,66 & 3,18 & 2,89 \\
\hline Pluriativo & 12,4 & 62,9 & 28,6 & 20 & 15 & 35 & 25 & 44 & 40 & 1,25 & 1,00 & 2,50 & 1,66 & 3,18 & 2,91 \\
\hline Sem Ocup. & 13,4 & 61,0 & 57,6 & 20 & 12 & 35 & 24 & 40 & 40 & 1,25 & 0,83 & 2,12 & 1,25 & 3,18 & 2,55 \\
\hline \multicolumn{16}{|l|}{ Urbano } \\
\hline Não agrícola & 74,7 & 59,1 & 13,6 & 20 & 15 & 36 & 25 & 44 & 40 & 2,08 & 1,87 & 2,89 & 2,89 & 3,64 & 3,64 \\
\hline Agrícola & 8,6 & 62,1 & 16,4 & 20 & 12 & 40 & 26 & 44 & 40 & 1,59 & 1,25 & 2,71 & 2,50 & 3,32 & 3,18 \\
\hline Pluriativo & 10,1 & 58,3 & 14,7 & 20 & 18 & 35 & 30 & 42 & 40 & 1,87 & 1,41 & 2,89 & 2,57 & 3,64 & 3,18 \\
\hline Sem Ocup. & 6,8 & 64,5 & 9,7 & 24 & 18 & 40 & 30 & 44 & 40 & 1,97 & 1,60 & 2,89 & 2,83 & 3,54 & 3,50 \\
\hline
\end{tabular}

Fonte: elaboração própria a partir dos microdados do Censo Demográfico de 2010. (1) Proporção de crianças e adolescentes residentes nos setores domiciliares, (2) Proporção do sexo Masculino (M), (3) Sem remuneração monetária e, finalmente, (4) Quartis.

Em todas as regiões e setores observam-se discriminação na remuneração monetária, com as crianças do sexo feminino recebendo por hora trabalhada menos que os homens. E considerando o valor do salário mínimo bruto por hora trabalhada de $\mathrm{R} \$$ 3,10, observam-se, em todos os setores e mais intenso na região rural, a baixa remuneração das crianças.

As informações da tabela 7, que descrevem as diferenças de raça, demonstram que para todas os setores a maioria das crianças e adolescentes que trabalham é da raça parda ou negra. Em relação as horas trabalhadas não se verificou discrepâncias entre as raças, mas com relação à remuneração, as crianças negras e pardas recebem retornos monetários menores que as crianças brancas. 
Tabela 7 - Características socioeconômicas das crianças e adolescentes que exercem alguma atividade laboral, considerando a raça e o setor de ocupação domiciliar nas regiões rural e urbana do estado, 2010

\begin{tabular}{|c|c|c|c|c|c|c|c|c|c|c|c|c|c|c|c|}
\hline \multicolumn{16}{|l|}{ Setor domic. } \\
\hline & \multirow{3}{*}{$\begin{array}{c}\text { Prop }{ }^{1} . \\
(\%)\end{array}$} & \multirow{3}{*}{$\begin{array}{c}\operatorname{Raça}^{2} \\
\text { B (\%) }\end{array}$} & \multirow{3}{*}{$\begin{array}{c}\text { S.Rem } \\
(\%) \\
\end{array}$} & \multicolumn{6}{|c|}{ Horas na semana } & \multicolumn{5}{|c|}{ Remuneração hora } & \multirow{2}{*}{$\begin{array}{l}(\mathbf{R} \$) \\
\text { Q. }\end{array}$} \\
\hline & & & & \multicolumn{2}{|c|}{$1 Q^{4}$} & \multicolumn{2}{|c|}{2 Q. } & \multicolumn{2}{|c|}{$3 \mathrm{Q}$} & \multicolumn{2}{|c|}{$1 \mathrm{Q}$} & \multicolumn{2}{|c|}{2 Q. } & 3 Q. & \\
\hline & & & & B & $\mathbf{O}$ & B & $\mathbf{O}$ & B & $\mathbf{O}$ & B & $\mathbf{O}$ & B & $\mathbf{O}$ & B & $\mathbf{O}$ \\
\hline \multicolumn{16}{|l|}{ Rural } \\
\hline Não agrícola & 32,3 & 41,6 & 24,1 & 20 & 20 & 30 & 30 & 40 & 40 & 1,38 & 1,04 & 2,45 & 1,87 & 3,18 & 3,00 \\
\hline Agrícola & 41,9 & 37,9 & 41,1 & 18 & 15 & 30 & 30 & 42 & 40 & 1,32 & 1,04 & 2,50 & 1,87 & 3,18 & 3,12 \\
\hline Pluriativo & 12,4 & 40,6 & 28,6 & 20 & 16 & 30 & 30 & 43 & 40 & 1,36 & 1,07 & 2,50 & 1,87 & 3,18 & 3,12 \\
\hline Sem Ocup. & 13,4 & 42,2 & 57,6 & 20 & 18 & 30 & 30 & 40 & 40 & 1,20 & 1,04 & 2,08 & 1,87 & 3,12 & 3,12 \\
\hline \multicolumn{16}{|l|}{ Urbano } \\
\hline Não agrícola & 74,7 & 38,5 & 13,6 & 20 & 20 & 30 & 30 & 40 & 42 & 2,14 & 1,87 & 3,00 & 2,89 & 3,75 & 3,54 \\
\hline Agrícola & 8,6 & 36,5 & 16,4 & 20 & 18 & 35 & 34,1 & 44 & 44 & 1,70 & 1,25 & 2,84 & 2,55 & 3,75 & 3,18 \\
\hline Pluriativo & 10,1 & 35,2 & 14,7 & 20 & 20 & 30 & 30 & 40 & 40 & 1,87 & 1,56 & 2,89 & 2,65 & 3,75 & 3,27 \\
\hline Sem Ocup. & 6,8 & 33,2 & 9,7 & 20 & 20 & 36 & 40 & 44 & 44 & 2,00 & 1,75 & 2,89 & 2,67 & 3,90 & 3,33 \\
\hline
\end{tabular}

Fonte: elaboração do autor a partir dos microdados do Censo Demográfico de 2010. (1) Proporção de crianças e adolescentes residentes nos setores domiciliares, (2) Raça branca (B) e parda ou negra (O), (3) Sem remuneração monetária e, finalmente, (4) Quartis.

A tabela 8, ao demonstrar as condições de ocupações das crianças considerando os setores de atividades domiciliares nos territórios rural e urbano, permite inferir sobre o grau de vulnerabilidade que as crianças se deparam nas relações de trabalho ${ }^{\mathrm{x}}$. A condição de ocupação empregado, com ou sem carteira assinada, refere-se à criança que trabalhava para um empregador (pessoa física ou jurídica), geralmente obrigando-se ao cumprimento de uma jornada de trabalho e recebendo, em contrapartida, uma remuneração em dinheiro, mercadoria, produtos ou benefícios (moradia, alimentação, vestuário, treinamento etc.). Essa condição de ocupação, considerando a situação em que as crianças não têm carteira de trabalho, é a que mais se verifica em todos os setores de domicílios e regiões, com exceção para os sem ocupações na região rural. Somando-se a isso a significativa proporção de crianças sem remuneração, com maior incidência na região rural, podemos concluir que as relações de trabalho das crianças no estado são caracterizadas pela vulnerabilidade, predominando o serviços à margem da legislação trabalhista e sem remuneração. 
Caracterizações socioeconômica e espacial do trabalho infantil nas regiões rurais e urbanas do estado de Minas Gerais

Tabela 8 - Proporção de crianças e adolescentes segundo as condições de ocupações por setor de atividade nos territórios rural (R) e Urbano (U) do estado de Minas Gerais, 2010

\begin{tabular}{lccccccc}
\hline Setor domicílio & & $\begin{array}{c}\text { Com } \\
\text { Carteira }\end{array}$ & $\begin{array}{c}\text { Sem } \\
\text { Carteira }\end{array}$ & $\begin{array}{c}\text { Conta } \\
\text { Própria }\end{array}$ & $\begin{array}{c}\text { Emprega- } \\
\text { dores }\end{array}$ & $\begin{array}{c}\text { Não Remu- } \\
\text { nerados }\end{array}$ & $\begin{array}{c}\text { Cons. } \\
\text { Próprio }\end{array}$ \\
\hline \multirow{2}{*}{ Não agrícola } & $\mathbf{R}$ & 10,7 & 59,9 & 8,4 & 0,1 & 11,6 & 9,4 \\
& $\mathbf{U}$ & 26,9 & 50,0 & 11,2 & 0,3 & 10 & 1,7 \\
\hline \multirow{2}{*}{ Agrícola } & $\mathbf{R}$ & 6,6 & 41,6 & 16,7 & 0,1 & 18,1 & 16,9 \\
& $\mathbf{U}$ & 22,2 & 53,2 & 10,5 & 0 & 9,1 & 5,0 \\
\hline \multirow{2}{*}{ Pluriativo } & $\mathbf{R}$ & 9,5 & 54,8 & 11,1 & 0 & 12,7 & 11,9 \\
& $\mathbf{U}$ & 21,4 & 54,2 & 12,9 & 0,1 & 9 & 2,5 \\
\hline \multirow{2}{*}{ Sem Ocupação } & $\mathbf{R}$ & 4,9 & 38,7 & 4,2 & 0,1 & 5,5 & 46,6 \\
& $\mathbf{U}$ & 24,5 & 58,6 & 9,4 & 0,1 & 2,4 & 5,0 \\
\hline
\end{tabular}

Fonte: elaboração do autor a partir dos microdados do Censo Demográfico de 2010.

\section{Análise espacial da alocação do tempo das crianças nos municípios mineiros}

Essa seção descreve a estrutura espacial dos quatro estratos da alocação do tempo das crianças e adolescentes nos 853 municípios mineiros. Para tanto, através dos Box Maps, e da Análise AEDE, onde foram estimados a Autocorrelação Global Univariada, por meio do I de Moran e os LISA, foi possível identificar os agrupamentos espaciais significantes de valores similares em torno da estrutura da alocação do tempo nos municípios.

\section{Estrutura da alocação do tempo das crianças nos municípios mineiros}

Minas Gerais é um estado de grande extensão territorial, composto de 853 municípios, com condições geográficas e socioeconômicas heterogêneas. Nesta seção do trabalho, demonstra-se como ocorrem, em cada município, os quatro estratos de alocação do tempo das crianças entre trabalho e estudo. Para tanto, foram utilizados os Box Maps, que dividem os municípios em quatro grupos, assumindo o critério hinge de 1,5. Ou seja, serão considerados outlier superior toda observação que superar o intervalo interquartílico 1,5 vezes $^{\mathrm{xi}}$. A tabela 10 descreve as estatísticas básicas dos estratos de alocação do tempo das crianças, importantes para a interpretação dos mapas a serem apresentados a seguir.

A incidência do estrato não estuda e não trabalha (NENT), em relação à população total de crianças e adolescentes, apresentou, para os 853 municípios do estado, média de $5,4 \%$, com participação máxima de $17,2 \%$ e mínima de $0,8 \%$. Os valores do primeiro, segundo e terceiro quartis foram, respectivamente de $3,9 \%, 5,2 \%$ e $6,6 \%$, demonstrando 
que um quarto dos municípios tem mais de 6,6\% de crianças e adolescentes em situação de alta vulnerabilidade, pois nem estudam e nem trabalham. Esses municípios, representados na figura 2 pelas cores laranja, estão mais concentrados nas mesorregiões do Jequitinhonha, Norte de Minas, Vale do Mucuri, Vale do Rio Doce, Zona da Mata e Triângulo Mineiro. Verificaram-se vinte e um municípios caracterizados como outlier superiores, representados na cor vermelha.

Tabela 10 - Estatísticas básicas dos estratos de alocação do tempo das crianças e adolescentes entre estudo e trabalho, municípios do estado de Minas Gerais, 2010

\begin{tabular}{llllllll}
\hline & Média & Máximo & Mínimo & D. padrão & 1 Quartis & 2 Quartis & 3 Quartis \\
\hline NENT & 5,49 & 17,26 & 0,80 & 1,73 & 3,97 & 5,20 & 6,69 \\
ENT & 79,42 & 93,02 & 54,03 & 5,14 & 75,69 & 79,93 & 84,17 \\
NET & 3,49 & 15,96 & 0,00 & 1,53 & 2,09 & 3,06 & 4,47 \\
ET & 11,62 & 38,85 & 1,61 & 3,96 & 8,04 & 10,85 & 14,71 \\
\hline
\end{tabular}

Fonte: elaboração própria a partir dos dados da pesquisa.

Para o estrato de alocação do tempo das crianças e adolescentes não estudam e trabalham (NET), segundo a tabela 10, o percentual médio dos municípios foi de 3,5\% com valor máximo de $15,9 \%$ e o mínimo de zero. Os valores do primeiro, segundo e terceiro quartis foram de, respectivamente, $2 \%, 3 \%$ e 4,4\%, demonstrando que metade dos municípios apresenta o percentual de crianças que não estudam e trabalham abaixo $\operatorname{dos} 3 \%$.

Figura 2 - Box Map do percentual de crianças e adolescentes que não estudam e não trabalham (NENT) nos municípios do estado de Minas Gerais no ano de 2010

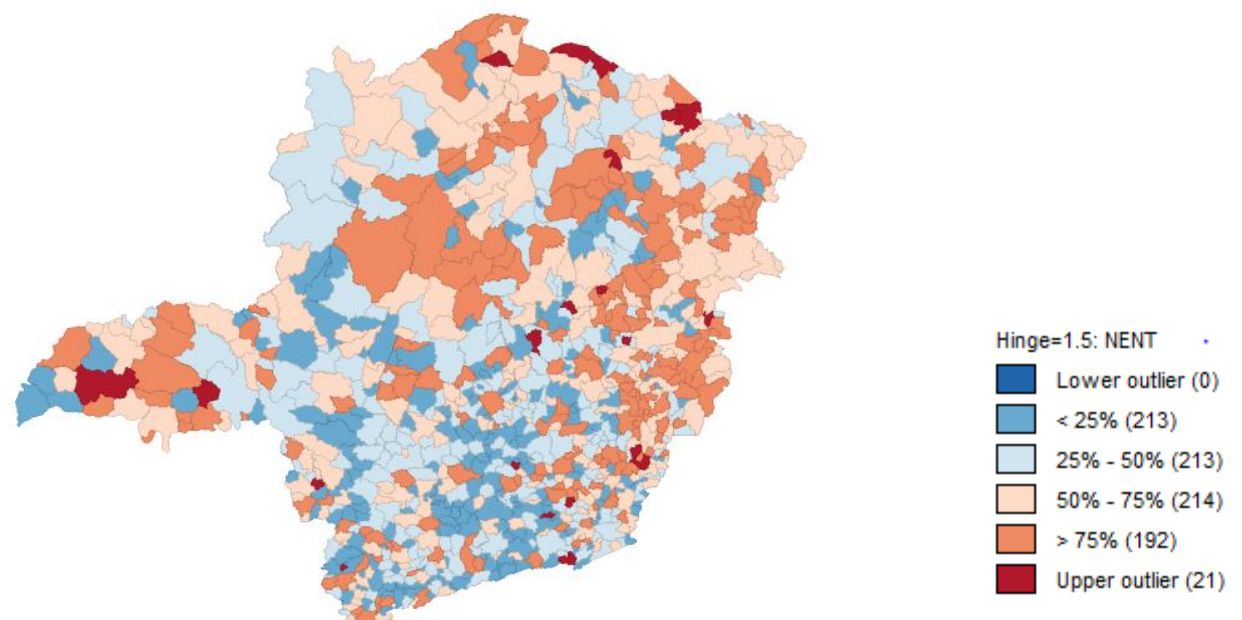

Fonte: elaboração própria, utilizando o software GEODA. 
Esses municípios, segunda a figura 3, estão mais concentrados, representados nas cores azul escuro e claro, nas regiões Metropolitana de Belo Horizonte, Campo das Vertentes e Central Mineira. As maiores incidências desse estrato foram localizadas no Triângulo Mineiro, Sul de Minas e Zona da Mata, sendo que dos 30 municípios outlier superiores, a maioria se concentra nessas regiões.

Figura 3 - Box Map do percentual de crianças e adolescentes que não estudam e trabalham (NET) nos municípios do estado de Minas Gerais no ano de 2010

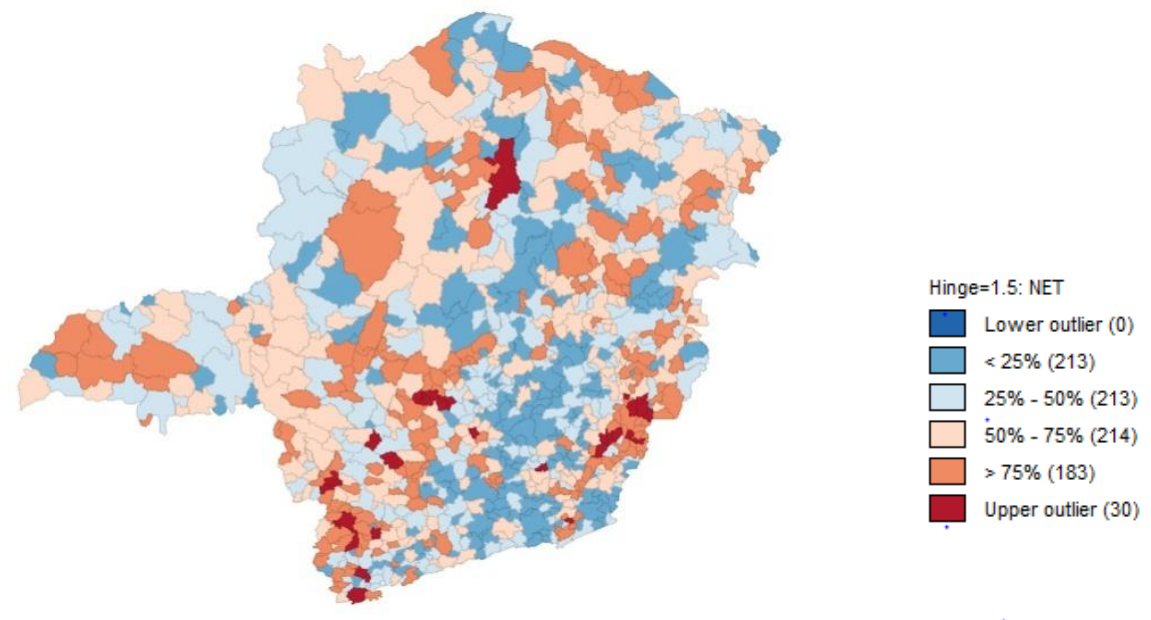

Fonte: elaboração própria, utilizando o software GEODA.

O nível de ocorrência do estrato estuda e trabalha (ET), em relação à população total de crianças e adolescentes, foi em média, para os municípios, da ordem de 11,6\%, com o nível máximo de 38,8\% e o mínimo de 1,6\%. Os valores dos primeiros, segundo e terceiro quartis foram, respectivamente, de $8 \%, 10,8 \%$ e 14,7\%. Isso significa que a metade dos municípios apresentam mais de $10 \%$ da população de crianças e adolescentes conciliando o estudo com alguma atividade laboral, e destes, mais da metade, ou seja $25 \%$ dos municípios, apresentam incidência de mais de 14,7\%. Esses municípios, apresentados na figura 4 nas cores bege, laranja e vermelha, estão concentrados nas regiões do Triângulo Mineiro, Sul de Minas, Zona da Mata, Noroeste de Minas, Norte de Minas e Jequitinhonha, sendo que nestas duas últimas regiões se concentram os outlier superiores. 
Figura 4 - Box Map do percentual de crianças e adolescentes que estudam e trabalham (ET) nos municípios do estado de Minas Gerais no ano de 2010

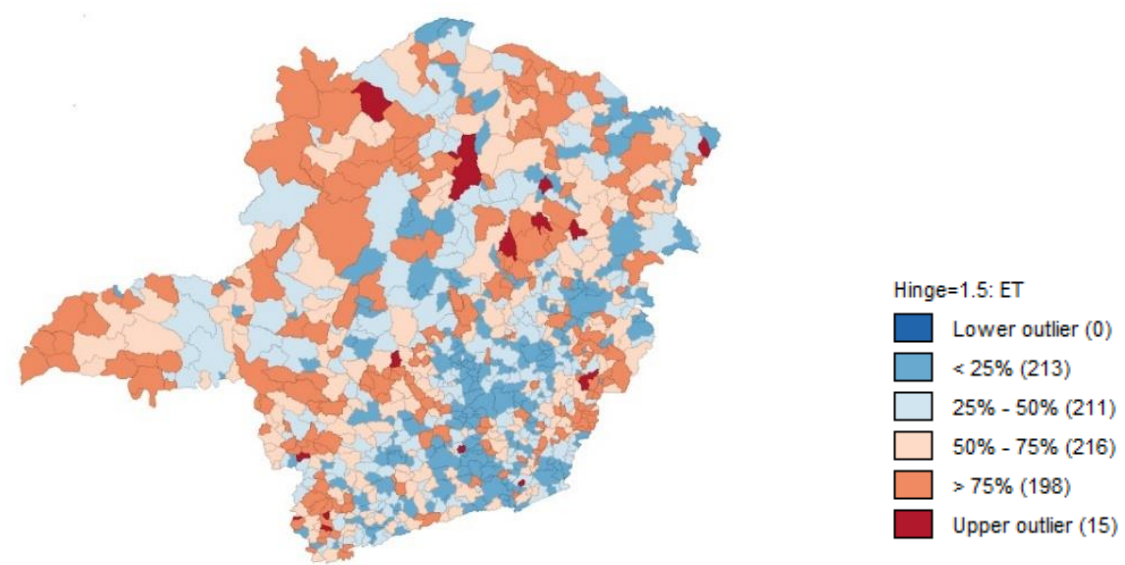

Fonte: elaboração própia, utilizando o software GEODA.

Para o estrato estuda e não trabalha (ENT), o mais desejável para que as crianças e adolescentes possam dedicar exclusivamente aos estudos, o nível médio, segundo a tabela 10, para os municípios foi de 79,4\%, com valor máximo de $93 \%$ e mínimo de $54 \%$. O primeiro, segundo e terceiro quartis apresentaram, respectivamente, os valores de $75,6 \%, 79,9 \%$ e $84,1 \%$, demonstrando que mais da metade dos municípios têm mais de 80\% da população de crianças e adolescentes apenas estudando. Esses municípios, representados na figura 5 nas cores bege e laranja, estão concentrados nas regiões Metropolitana de Belo Horizonte, Campo das Vertentes, Oeste de Minas e parte da Zona da Mata. Por outro lado, os municípios com valores abaixo de 75,6\%, primeiro quartil, apresentados em azul, estão localizados no Triângulo Mineiro, Norte de Minas Jequitinhonha, Parte da Zona da Mata e Sul de Minas.

Figura 5 - Box Map do percentual de crianças e adolescentes que estudam e não trabalham (ENT) nos municípios do estado de Minas Gerais no ano de 2010

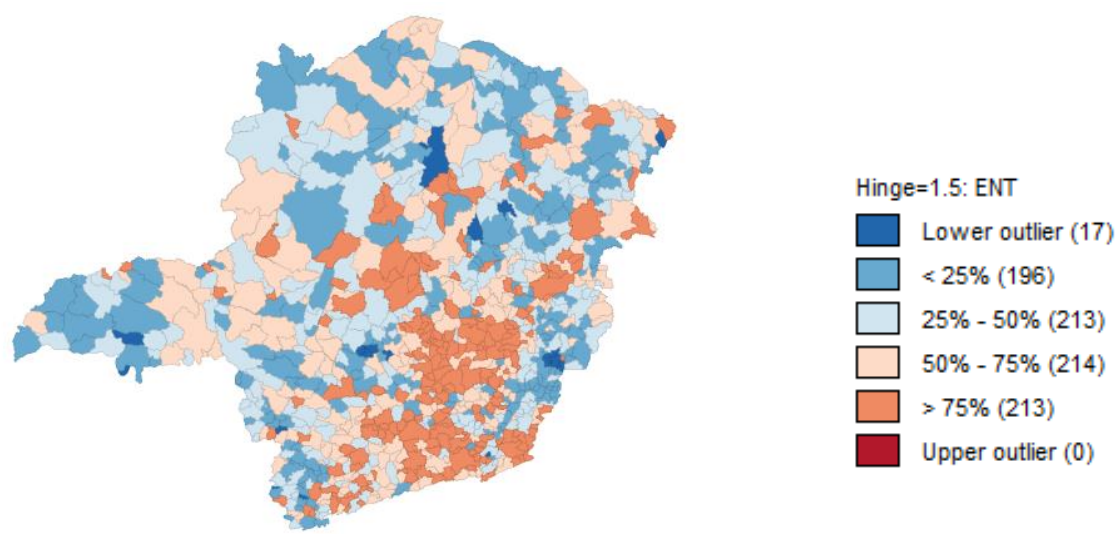

Fonte: elaboração própria, utilizando o software GEODA. 
Em síntese, a partir da inspeção visual das figuras 2 a 5, foi possível verificar que a vulnerabilidade das crianças, representadas pelos estratos ET e NET, concentra-se nos municípios localizados no Triangulo Mineiro, Norte de Minas, Zona da Mata e Sul de Minas. A incidência do NENT ocorre mais nos municípios das regiões Norte de Minas e Jequitinhonha. E, finalmente, a condição ENT, a mais desejada, apresenta mais incidência nos municípios da região Metropolitana de Belo Horizonte, Central e Campo das vertentes. Tendo em vista o grande número de municípios no estado, seria mais adequado e seguro, em vez de utilizar a análise visual, adotar o método da Análise Exploratória de Dados Espaciais, para verificar o padrão de dependência espacial e a existência de cluster para os estratos de ocupações.

\section{Análise Exploratória de Dados Espaciais (AEDE)}

A dependência no espaço é multidirecional e recíproca. A reciprocidade é dada pelo fato de que a região influencia o seu vizinho e é por ele influenciada. Sendo assim, espera-se que os quatro estratos de alocação do tempo das crianças nos municípios influenciem e sejam influenciados significativamente pelas regiões vizinhas. Dentro deste contexto, são analisadas a Autocorrelação Espacial Global Univariada dos municípios da região e, posteriormente, os Indicadores Locais de Associação Espacial (LISA).

Por intermédio da estatística I de Moran, apresentada na tabela 11, é possível verificar a existência de autocorrelação espacial dos quatro estratos de alocação do tempo das crianças e adolescente no estado de Minas Gerais. Para o cálculo da estatística utilizou-se a matriz de peso espacial rainha, com contiguidade de ordem 1 . O indicador varia de -1 a 1 , sendo que os valores positivos denotam estrutura espacial onde municípios com alto valor para os estratos de alocação do tempo das crianças seriam vizinhos de municípios também com altos valores para esses atributos e, por outro lado, municípios com baixos indicadores para os estratos teriam como vizinhos municípios também com baixos indicadores.

Todos os estratos de alocação do tempo das crianças e adolescente apresentaram correlação positiva, com significância estatística superior a 0,001\%. A menor correlação, com I de Moran de 0,1157, foi do estrato não estuda e não trabalha, NENT. O estrato estuda e trabalha, ET, apresentou coeficiente de 0,2392, e os estratos não estuda e trabalha, NET, e estuda e não trabalha. ENT, com as maiores correlações, apresentaram, respectivamente, coeficientes de 0,2987 e 0,3254 . 
Tabela 11 - Coeficiente I de Moran univariado dos estratos de alocação do tempo das crianças e adolescentes entre estudo e trabalho, municípios de Minas Gerais, 2010

\begin{tabular}{cc}
\hline Estratos & I de Moran \\
\hline NENT & 0,1157 \\
ENT & 0,3254 \\
NET & 0,2987 \\
ET & 0,2392 \\
\hline
\end{tabular}

Fonte: elaboração própria a partir dos dados da pesquisa. Todos os coeficientes apresentaram significância estatística superior a $0,001 \%$, obtidas a partir de 999 permutações aleatórias.

O coeficiente I de Moran, que representa a medida global de associação linear, é derivado do diagrama de dispersão, através da declividade da reta de regressão da variável de interesse em relação à média dos atributos dos vizinhos. Além dessa reta, o diagrama fornece também a informação de quatro tipos de associação linear espacial: Alto-Alto (AA), Baixo-Baixo (BB), Alto-Baixo (AB) e Baixo-Alto (BA). O mapa de Cluster LISA ilustra essas quatro categorias de associação espacial, combinando a informação do diagrama de dispersão com o mapa de significância das medidas de associação local. Nessa análise, utilizou-se o nível de significância de 5\%, ou seja, os clusters persistentes a este nível de significância mereceram maior atenção.

Figura 6 - Mapas de Cluster para os estratos de alocação do tempo das crianças e adolescentes para estudo e trabalho (ET) e não estudo e trabalho (NET), municípios do estado de Minas Gerais, 2010

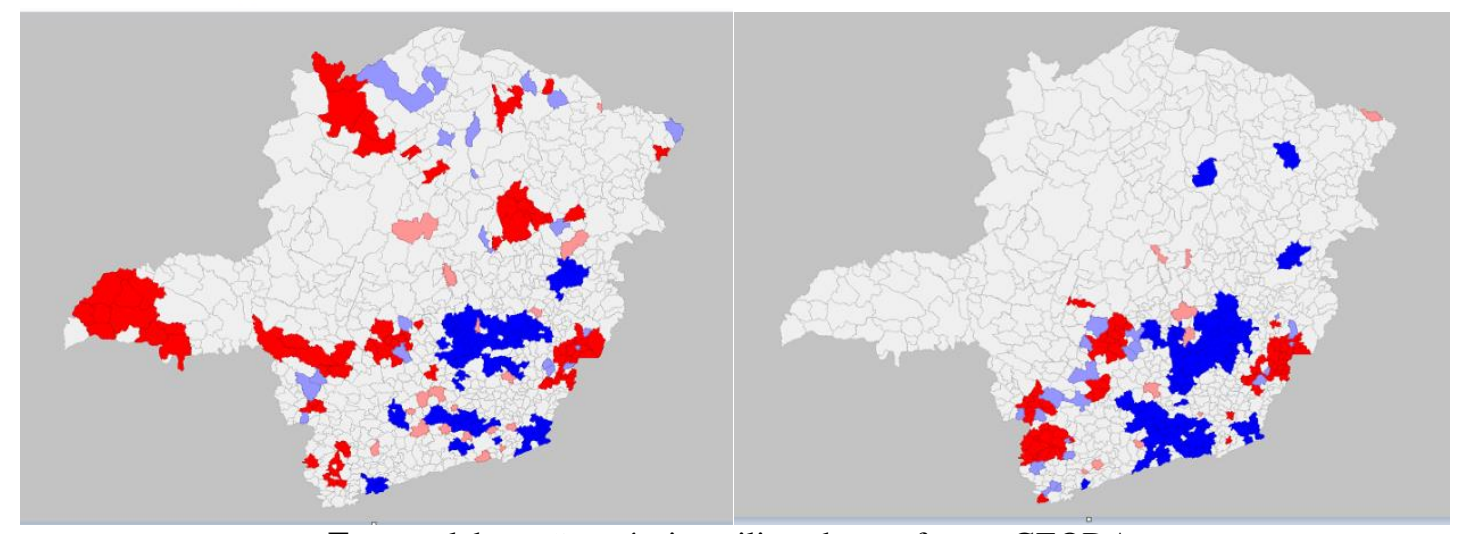

Fonte: elaboração própria, utilizando o software GEODA.

Na figura 6, são apresentados os mapas de Cluster lisa para os estratos estudo e trabalho, (ET), e não estudo e trabalho, (NET). Os municípios com associação espacial Alto-Alto, (AA), são representados em vermelho; os Baixo-Baixo, (BB), em azul; os Baixo-Alto, (BA), em roxo, e, finalmente, Alto-Baixo, (AB), em rosa. Os demais municípios, em branco, não apresentaram significância estatística a 5\%. Após essa notação, é possível observar para o estrato (ET) a formação majoritária dos grupos Alto- 
Alto e Baixo-Baixo. Os Alto-Alto, ou seja, agrupamento de municípios com alta incidência de crianças que trabalham e estudam, com vizinhos com esse mesmo atributo, representados em vermelho, estão localizados nas regiões do Triangulo Mineiro, Sul de Minas, Oeste de Minas, Zona da Mata, Noroeste de Minas e, finalmente, Jequitinhonha.

Os agrupamentos Baixo-Baixo, representados em azul, estão concentrados nas regiões Metropolitana, Zona da Mata e Campo das Vertentes. No caso do mapa para o estrato não estuda e trabalha, NET, observa-se o aumento dos agrupamentos para o BaixoBaixo e a concentração dos agrupamentos Alto-Alto nas regiões do Sul de Minas, Oeste de Minas e Zona da Mata. A identificação das localidades onde concentram o trabalho infantil é importante como sinalização para o setor público voltar a suas ações para essas regiões e, como propostas de futuras pesquisas, analisar de forma mais detalhada os condicionantes sociais e econômicos do trabalho infantil nessas localidades.

Figura 7 - Mapas de Cluster para os estratos de alocação do tempo das crianças e adolescentes para não estuda e não trabalha (NENT) e estuda e não trabalha (ENT), municípios do estado de Minas Gerais, 2010

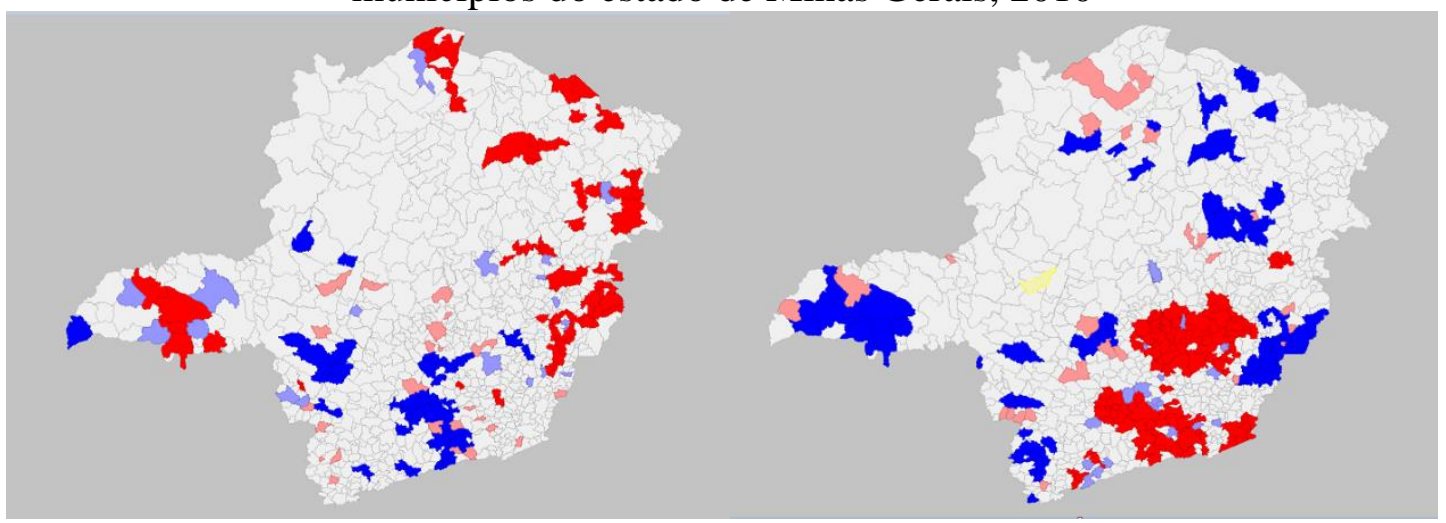

Fonte: elaboração dos autores, utilizando o software GEODA.

A figura 7 apresenta os mapas de Cluster para os estratos não estuda e não trabalha, (NENT) e para estuda e não trabalha, (ENT). No primeiro caso, que apresenta a maior vulnerabilidade, tendo em vista que são crianças e adolescentes sem nenhuma atividade, os agrupamentos de municípios Alto-Alto estão localizados no Norte de Minas, Jequitinhonha, Vale do Mucuri, Vale do Rio Doce, Zona da Mata e Triangulo Mineiro. Essa última região, diferente das demais, é caracterizada por alto nível de atividade econômica e baixo nível de pobreza, demonstrando que a vulnerabilidade das crianças não está localizada apenas nas regiões menos favorecidas do estado e que os seus fatores determinantes são complexos e multidimensionais. O estrato estuda e não trabalha, (ENT), o mais desejado, tendo em vista que as crianças e adolescentes estariam alocando 
o tempo apenas para o estudo, apresenta os agrupamentos Alto-Alto localizados nas regiões Metropolitana, Campo das Vertentes e parte da Zona da Mata. Os agrupamentos Baixo-Baixo, para esse estrato, estão localizados no Norte de Minas, Jequitinhonha, Zona da Mata e Triangulo Mineiro.

\section{Conclusões}

O estudo, ao assumir a pressuposição que o trabalho infantil, independente da região e do nível de desenvolvimento econômico, trata-se de um fenômeno complexo e de difícil interpretação devido aos seus múltiplos fatores determinantes, buscou identificar alguns destes fatores para o estado de Minas Gerais, assumindo delimitação alternativa para os territórios rural e urbano.

A medida oficial subestima o tamanho da população rural no estado e apresenta um quadro de sua dimensão territorial que não condiz com a realidade quando assumimos no seu conceito, além da dimensão administrativa, as características de densidade demográfica e contingência populacional. As discrepâncias das medidas dos territórios rural e urbano diante da escolha de conceitos e metodologias distintas influenciam os estudos e, como consequência, o diagnóstico e a proposição de políticas públicas adequadas para tratar a diversidades territoriais no estado. No caso do estudo do trabalho infantil, essa distinção se faz de suma importância para identificar as características territoriais e compreender a sua influência na inserção das crianças e adolescentes no mercado de trabalho visando a elaboração de estratégias que busquem propor medidas eficientes para combater e solucionar o problema.

Em síntese, verifica-se que o trabalho infantil no estado de Minas Gerais, em todos os setores de atividades, especialmente nos domicílios agrícolas, é caracterizado por uma relação de vulnerabilidade onde, além da inserção prematura no mercado de trabalho, as crianças enfrentam a falta de registro, a exploração, tanto pelos baixos rendimentos quanto pela falta de remuneração, e o trabalho de subsistência. Essa relação de vulnerabilidade ocorre também nas regiões urbanas, mas é mais intensa nas regiões rurais do estado.

A partir da análise espacial, podemos afirmar que a estrutura dos quatro estratos de ocupação das crianças e adolescentes, segundo o coeficiente I de Moran univariado, apresenta correlação positiva, ou seja, municípios com indicadores altos apresentam vizinhos com esse mesmo atributo e os municípios com indicadores baixo apresentam, da 
mesma forma, vizinhos também com indicadores baixos. Os mapas de Cluster Lisa

demonstraram que a alocação mais vulnerável do tempo das crianças e adolescentes, representadas pelos estratos (NENT), (NET) e (ET), está concentrada nas regiões Norte, Jequitinhonha, Zona da Mata e Triangulo Mineiro e, por outro lado, o estrato mais favorável, (ENT), concentra-se nas regiões Metropolitana, Campo das Vertente e parte da Zona da Mata.

\section{Notas}

${ }^{1} \mathrm{O}$ trabalho apresenta resultados parciais do projeto de pesquisa "Determinantes do trabalho infantil em Minas Gerais", coordenado pelo autor e financiado pelo FAPEMIG - Edital Universal 2015.

${ }^{2} \mathrm{O}$ artigo $7^{0}$ da Constituição Federal de 1988 proíbe ao menor de 18 anos o trabalho noturno, perigoso ou insalubre e de qualquer trabalho aos menores de 16 anos, salvo a partir de 14 anos na condição de menor aprendiz.

${ }^{3}$ Muniz (2012), dentro da perspectiva da classificação sociológica, faz uma minuciosa revisão bibliográfica de trabalhos relacionados com os diversos fatores determinantes do trabalho infantil, tanto de origem interna quanto externa, para vários países. Para o Brasil, o autor destaca os seguintes estudos Bezerra (2000), Di Giovani (2002), Fernandes \& Souza (2003), Ferro \& Kassouf (2003), Kassouf (2002) e Muniz (2006).

${ }^{4}$ Segundo Abramovay (2003) e Veiga (2003), o surgimento de cidades de tamanho irrisório e a delimitação oficial levam a idéia equivocada que, em 2000, o nível de urbanização teria atingido $81 \%$ da população brasileira.

${ }^{5}$ Ney \& Hoffmann (2009), no estudo sobre os fatores determinantes da renda rural, utilizam também esse critério para a delimitação dos territórios urbano e rural.

${ }^{6}$ A partir das pressuposições do modelo unitário, torna-se possível estimar funções de demanda por consumo de bens e serviços, demanda de lazer e oferta de trabalho, demonstrando a alocação do tempo dos membros da família Desse modo, o modelo preocupa-se apenas com as decisões entre as famílias e não leva em consideração como os recursos são distribuídos no âmbito interno dos domicílios.

${ }^{7}$ Para informações mais detalhadas sobre essas pressuposições ver Mas-colell, Whinston \& Green (1995), capítulo 3. Como exemplo, podemos citar a crescente participação da mulher no mercado de trabalho, onde a decisão da família passa a depender da forma da alocação do seu tempo, em acordo com os demais membros.

${ }^{8}$ A definição do que seja rural e urbano está associada a duas linhas teóricas: a dicotômica e a de continuum. A primeira ressalta as diferenças ou os contrastes entre esses dois espaços, sendo o território rural pensado como algo que se opõe ao urbano. Na segunda linha, ao contrário, verifica-se uma aproximação da realidade desses dois espaços (Bertrand, 1973). As profundas transformações socioespaciais observadas ao longo do século XX, caracterizadas pelo crescimento das cidades, pela industrialização da agricultura, e pelo transbordamento do urbano nas áreas rurais, verificados de forma marcante também no Brasil, levaram a uma nova interpretação das definições territoriais. Com isso a visão dicotômica passa a dar lugar à interpretação teórica do espaço continuum, onde a polarização antagônica é substituída por um complexo gradiente de variações espaciais. A metodologia proposta por Ney e Hoffmann (2009) vai de encontro a essa última interpretação.

${ }^{9}$ Essa definição das ocupações domiciliares foi utilizada também no Atlas da extrema pobreza no Norte e Nordeste do Brasil em 2010, (IPC-IG, PNUD, 2015).

${ }^{x}$ Segundo a definição metodológica das condições de ocupação do Censo, considera-se Empregado a pessoa que trabalhava para um empregador (pessoa física ou jurídica), geralmente obrigando-se ao cumprimento de uma jornada de trabalho e recebendo, em contrapartida, uma remuneração em dinheiro, mercadoria, produtos ou benefícios (moradia, alimentação, vestuário, treinamento, etc.); Conta própria a pessoa que trabalhava explorando o seu próprio empreendimento, sozinha ou com sócio, sem ter empregado, ainda que contando com ajuda de trabalhador não remunerado; Empregador a pessoa que trabalhava explorando o seu próprio empreendimento com pelo menos um empregado; Não remunerado a pessoa que trabalhou sem remuneração, durante pelo menos uma hora completa na semana de referência, em ajuda na atividade econômica de morador do domicílio que era conta própria, empregador ou empregado do setor privado;

CAMPO-TERRITÓRIO: revista de geografia agrária, v. 14, n. 32, p. 53-83, abr., 2019 
Próprio consumo - para pessoa que trabalhou, durante pelo menos uma hora completa na semana de referência, na produção de bens, em atividade da agricultura, pecuária, caça, produção florestal, pesca ou aquicultura, destinados somente à alimentação de, pelo menos, um morador do domicílio, (IBGE, 2012).

xi O intervalo interquartílico é definido como IIQ = Q3 -Q1, onde Q3 é o valor do terceiro quartil e Q1 o do primeiro quartil.

\section{Referências}

ABRAMOVAY, R. O futuro das regiões rurais. Porto Alegre, Editora UFRGS, 2003.

ARAUJO, A. A. O programa bolsa família e o trabalho infantil no Brasil. Tese de Doutorado, Programa de Pós-graduação em Economia Aplicada, Universidade Federal de Viçosa, Viçosa, MG, 2010.

BARROS, R. P.; MENDONÇA, R.; VELAZCO, T. Is poverty the main couse of child work in urban Brazil?. Texto para Discussão n. 131, Rio de Janeiro, IPEA, 1994.

BERTRAND, A. L. Sociologia Rural: uma análise da vida rural contemporânea. São Paulo, Brasil, Editora Atlas, 1973.

BEZERRA, M. A. P. Informe da comissão estadual de erradicação do trabalho infantil de Pernambuco. IN: ARREGUI, C. C. (org.). Erradicação do trabalho infantil: dimensionando as experiências de Pernambuco, Mato Grosso do Sul e Bahia. São Paulo, EDUC, IEE/PUC-SP: FINEP, 2000.

BHALOTRA, S.; HEADY, C. Child farm labor: the wealth paradox. The Wolrd Bank Economic Review, vol. 17, n.2, 2003.

DI GIOVANNE, G. (Coord.) Trabalho infantil em Campinas. Campinas: UNICAMP/IE, 2002.

FERNANDES, M. M. Estimação da oferta de trabalho com modelos coletivos: uma aplicação para o Brasil. Dissertação de mestrado, Departamento de economia da Universidade de São Paulo, Ribeirão Preto, SP, 100p. 2008.

FERNANDES, R.; SOUZA, A. P. A redução do trabalho infantil e o aumento da freqüência a escola: uma análise de decomposição para o Brasil nos anos 90. Julho de 2003. Disponível em www.econ.feausp.br/seminarios/artigos/portela.pdf.

FERRO, A. R.; KASSOUF, A. L. Avaliação do impacto dos programas de Bolsa Escola na indigência de trabalho infantil no Brasil. XXXI Encontro Nacional de Economia da ANPEC, Porto Seguro, BA, 09 a 12 de dezembro, 2003. Disponível em www.anpec.org.br/encontro 2003/ artigos.pdf.

IBGE. Instituto Brasileiro de Geografia e Estatística. Censo demográfico de 1991. Rio de Janeiro, 1998.

IBGE. Instituto Brasileiro de Geografia e Estatística. Censo Demográfico de 1991 e 2000. Rio de Janeiro: IBGE, 2004. 
IBGE. Instituto Brasileiro de Geografia e Estatística. Censo Demográfico de 2010. Rio de Janeiro: IBGE, 2012.

IPC-IG; PNUD. População residente em domicílios agrícolas, pluriativos, rurais não agrícolas e urbanos não agrícolas - Atlas da extrema pobreza no Norte e Nordeste do Brasil em 2010. Brasília: PNUD Brasil, 2015.

KASSOUF, A. L. Aspectos socioeconômicos do trabalho infantil no Brasil. Brasília: Secretaria de Estado dos Direitos Humanos, 2002.

MAS-COLELL, A.; WHINSTON, M.; GREEN, J. Microeconomic theory. Oxford: Orxford University, 1995.

MUNIZ, A. L. P. As características e os determinantes do trabalho infantil em Minas Gerais em 2004. Dissertação de mestrado, Instituto de Economia, Universidade Federal de Uberlândia, Uberlândia, MG, 215 p. 2006.

MUNIZ, A. L. P. Os determinantes do trabalho infantil: uma revisão bibliográfica. Revista da Rede de Estudos do Trabalho. Ano VI, n. 10, 2012.

NASCIMENTO, A. R.; KASSOUF, A. L. Trabalho infantil: impacto do programa bolsa família. In: Anais do XLII Encontro Nacional de Economia, ANPEC, Natal (RN), 2014.

NEY, M. G.; HOFFMANN, R. Educação, concentração fundiária e desigualdade de rendimento no meio rural. Revista de Economia e Sociologia Rural, Piracicaba, SP, vol. 47, n,01, p. 147-182, jan-mar 2009.

OIT BRASIL. Organização internacional do trabalho. Brasília, 2007. Acesso em 15 jun. 2016.

PNUD; IPEA; FJP. Atlas do Desenvolvimento Humano no Brasil. Brasília: PNUD Brasil, 2013.

ROCHA, L. E. V.; FONTES, R. M. O. Disparidades do desenvolvimento urbano e rural: uma análise espacial para as microrregiões do estado de Minas Gerais. Revista de Economia, v. 37, n. 1, Editora UFPR, p. 59-90, jan/abr, 2011.

VEIGA, J. E. Cidades imaginárias: o Brasil é menos urbano do que se calcula. Campinas, Autores Associados, 2003.

VERMEULEN, F. Collective household models principles and main results. Journal of Economics Survey, Edinburgh, 16(4), 533-64, 2002.

Recebido em 07/08/2018.

Aceito para publicação em 19/08/2019. 